University of Louisville

ThinkIR: The University of Louisville's Institutional Repository

Electronic Theses and Dissertations

$5-2021$

\title{
Incidental exposure, political activity and perceived trust.
}

\author{
Brianna Berry \\ University of Louisville
}

Follow this and additional works at: https://ir.library.louisville.edu/etd

Part of the Political Science Commons

\section{Recommended Citation}

Berry, Brianna, "Incidental exposure, political activity and perceived trust." (2021). Electronic Theses and Dissertations. Paper 3654.

https://doi.org/10.18297/etd/3654

This Master's Thesis is brought to you for free and open access by ThinkIR: The University of Louisville's Institutional Repository. It has been accepted for inclusion in Electronic Theses and Dissertations by an authorized administrator of ThinkIR: The University of Louisville's Institutional Repository. This title appears here courtesy of the author, who has retained all other copyrights. For more information, please contact thinkir@louisville.edu. 
INCIDENTAL EXPOSURE, POLITICAL ACTIVITY \& PERCEIVED TRUST

\author{
By \\ Brianna Berry \\ B.A., University of Louisville, 2018 \\ M.A., University of Louisville, 2021

\begin{abstract}
A Thesis
Submitted to the Faculty of the

College of Arts and Sciences of the University of Louisville

In Partial Fulfillment of the Requirements

For the Degree of
\end{abstract}

\author{
Master of Arts \\ In Political Science
}
Departments of Political Science
University of Louisville
Louisville, Kentucky

May 2021 



\title{
INCIDENTAL EXPOSURE, POLITICAL ACTIVITY \& PERCEIVED TRUST
}

\author{
By \\ Brianna Berry \\ A Thesis Approved on \\ April 28, 2021 \\ By the following Thesis Committee \\ Jason Gainous \\ Adam Enders \\ Ricky Jones
}




\section{ABSTRACT \\ INCIDENTAL EXPOSURE, POLITICAL ACTIVITY \& PERCEIVED TRUST \\ Brianna Berry}

May 7, 2021

The current study examines the concept of incidental versus traditional exposure to information through the context of a police brutality incident. Incidental exposure on social media is when a person is exposed to information or imagery without prior warning. It is hypothesized that 1) individuals who are incidentally exposed to a graphic police brutality event will be more likely to participate in politics and 2) will have lower perceived trust in the government.

This randomized study utilizes two treatments (incidental exposure and traditional exposure) and a control group. Analysis of the data shows that support for $\mathrm{H}_{1}$ is only found when control variables are included in the regression. Support for $\mathrm{H}_{2}$ is found with the treatments by themselves and with the controls, leading to the overall conclusion that incidental exposure to police brutality events has an effect on perceived trust of the police and government, but not willingness to participate in politics. 


\section{TABLE OF CONTENTS}

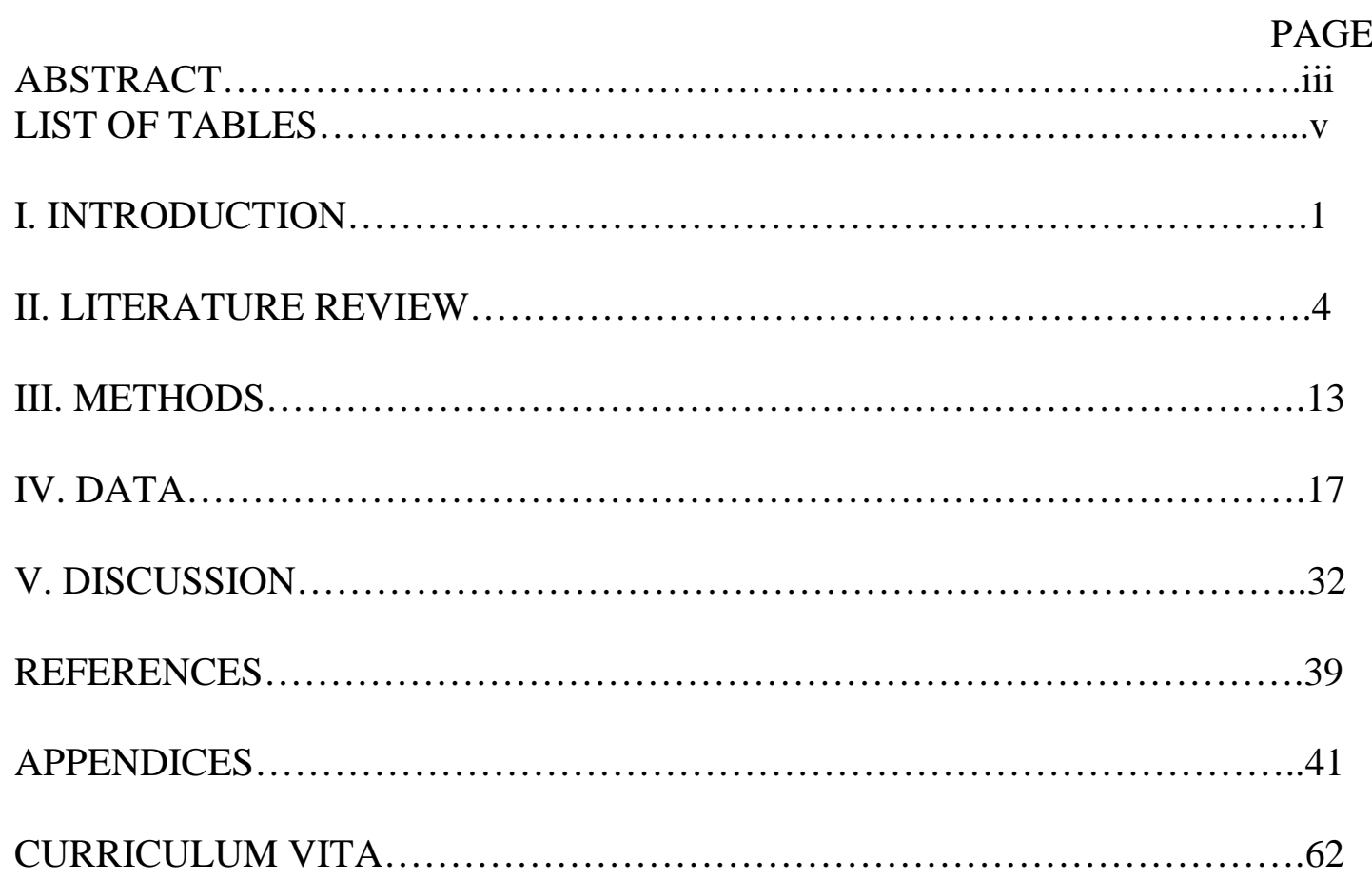




\section{LIST OF TABLES}

TABLE

PAGE

1. Mean Responses for Pre-Treatment Measure...............................20

2. Mean Responses for Dependent Variables...................................21

3. Bivariate Regression Models for Dependent Variables..........................23

4. Multivariate Regression Model for TEC vs. Control..........................25

5. Multivariate Regression Model for IEC vs. Control............................27

6. Multivariate Regression Model for IEC vs. TEC.............................29 


\section{INTRODUCTION}

Social scientists have always been interested in what causes change in human behavior. While there are many potential reasons why a person might act the way they do, the influence of the internet and social media cannot be ignored. It is now easier to feel connected to people you have never met and experience events you did not witness in person. One function of social media that has made this possible is the ability to share videos, images, and even live stream events. Thanks to this, social media users have the chance to witness events unfold in real time instead of reading about the event in a news article after the fact. This kind of phenomenon explains why a video posted on social media of George Floyd being held down and abused by Minneapolis police, ultimately causing his death, incited people to riot across the entire world, despite not witnessing the event in person. Experiencing an event in this manner has the possibility to evoke the same emotions and reactions that would have been produced if that individual was actually there, in person.

Information dissemination about current events can occur in multiple different ways. A more traditional way of exposure to information would include watching the news on the television or selecting a specific online or print article to read. Individuals are actively seeking out the information through social media or mass media sources and are mentally prepared to consume the content. Because traditional exposure is typically 
linked with mainstream media content, there is also an element of censoring extremely graphic or upsetting information or images.

Incidental exposure, on the other hand, is when an individual is accidentally exposed to something without preparation or a warning. Examples of this range from advertisements popping up in the middle of a YouTube video to scrolling on Facebook and seeing a graphic image someone has shared. Since it is accidental in nature, incidental exposure to events and information can have a strong effect on an individuals’ emotional response (Campbell \& Valera, 2020). If a person is actively seeking out information, particularly sensitive subject, then mentally, they are prepared to experience something that might be uncomfortable to see. Incidental exposure takes away this preparation time that an individual would have. It can be especially traumatic when the content an individual is incidentally exposed to is violent or graphic in nature. Incidental exposure has completely changed the way that individuals consume information. Instead of having to traditionally seek out the information themselves, social media has created a reality where virtually no one has control over the images, videos, and news articles that pop up on their screen.

Unfortunately, in today's world, a common type of violence that individuals can be incidentally exposed to on social media is police brutality. Violent interactions between the people and people of color have been happening since the creation of the police. However, with the evolution of social media, these types of events, specifically between police and unarmed Black Americans, are now being accounted for. A combination of witnesses filming interactions with the police and the growing pressure for police departments to release dashboard and body camera footage of violent incidents 
has allowed people from all across the world to witness the discrimination that people of color experience at the hands of the police. Incidental exposure to police brutality can be a catalyst that influences the way that individuals behave politically and perceive their trust in the government. This potential effect is the premise of the current study. The following chapter dives into the past literature on the above concepts before moving onto the design of the study, data, and discussion. 


\section{LITERATURE REVIEW}

In this study, I examined the possible relationship between incidental exposure to graphic events and political participation and perceived trust in the government. The type of graphic event I focused on was police brutality towards black people. In the past few years, live streaming and sharing capabilities have made instances of this type of violence extremely salient in all forms of the media. There are three essential concepts that tie into this research question: incidental exposure and social media use, graphic imagery and events, and the context of police interactions and brutality. These ideas have been looked at individually in past research. It is important to dive into the breadth that each concept has separately in order to understand the potential relationships that may be present in the current study.

\section{Incidental Exposure and Social Media Use}

As stated previously, incidental exposure differs from traditional exposure by incorporating an element of surprise. When the internet became a more widely used commodity, research began to focus on how news spread differently on the world wide web compared to the traditional tools of the media, such as newspapers and radio. A study conducted in 2001 examined how using the internet, whether actively or passively, impacted the amount of knowledge individuals had on current news (Tewksbury, Weaver, \& Maddox, 2001). In this instance, active usage is defined as when a person is utilizing the internet for the purpose of seeking information, whereas passive usage is 
when a person does not have motivation to become informed. As one could expect, the higher frequency of web use participants had, regardless if the usage was active or passive, the more likely they were to be incidentally exposed to news articles, therefore increasing their overall knowledge of current news. Most notable of this study is the conclusion that the "disparate range of activities... means that the Web provides the infrastructure for a much wider dissemination of breaking news headlines” compared to traditional media (Tewksbury et al., 2001). In this age of information at the fingertips of consumers, there is large potential for incidental exposure to news and events.

Social media has more specifically transformed the way that information is spread among consumers compared to general internet use. The influences of social media can be strong enough to alter users' behaviors depending on what and how they are exposed to different information. The ease of sharing political ideas on social media platforms not only increases the chances of individuals being incidentally exposed to news, but also allows for user to selective expose themselves to information that fits their beliefs. In 2017, a study was conducted using an online survey in the United States to compare how incidental exposure to challenging political information and selective exposure to affirming political information both effect the social media behaviors of individuals over time (Weeks, Lane, Kim, Lee, \& Kwak, 2017). The results of this study showed that individuals who are incidentally exposed to "attitude-challenging information [are likely] to seek like-minded political content” as a response (Weeks et al., 2017). This was especially true for those who identified strongly with their partisanship.

Incidental exposure to news on social media is not a phenomenon unique to the United States. A comparative study from 2017 focused in on individuals' exposure to 
news on social media from Italy, Australia, the United Kingdom, and the United States (Fletcher \& Nielsen, 2017). Participants were divided into three groups: news users, nonusers, or incidentally exposed users. New users, which were those who intentionally use social media to gather news, were left out in order to examine the potential effects of incidental exposure to the other two groups. Non-users are individuals who do not use social media at all; incidentally exposed users are individuals who use social media for reasons other than seeking out the news, which allows for the potential to come across news content. Honing in on Facebook, Twitter, and YouTube, this study found that the incidentally exposed group ended up interacting with significantly more online news sources than the non-user group (Fletcher \& Nielsen, 2017). This effect was stronger among users of YouTube and Twitter compared to Facebook, and there were minimal differences between the data from each country.

Social media is used for a multitude of reasons. People seek out friendships, networking opportunities, entertainment, information, and many more aspects across a wide range of platforms. The ease of sharing of information on social media networks has exponentially increased since its creation. This makes it crucial to the current study because of how intertwined social media use is with the spread of information. People connect to other users, whether they know them on a personal level or not, and therefore are exposed to a variety of different ideas and opinions. Part of this connection can be used to coordinate action and ideas among social movements, especially in cases of economic, environmental, and human justice. An examination of social media use conducted in 2012 supported this concept. In 2012, a large volume of information being shared on social media platforms focused on the words "occupy" and "inequality", and 
other words associated with protesting. The number of physical protests and political actions were rising at the same time that these trigger words were being shared more (Bennett, 2012). Essentially, social media has become the "loci of power in society, replacing hierarchical social and political institutions” because of the power that individuals have to formulate collective action and ideas amongst the platforms (Bennett, 2021).

The sharing of stories involving political motives or issues on social media allow more people to become informed on the issues, as well as get involved with the movements. Just as being exposed to new ideas might serve as an agent of change to someone’s opinion on an issue, exposure to potential political movements and actions might persuade a person to get involved themselves. Another study conducted in 2012 took the concept of social media use and compared it to social capital, civic participation, and political participation, both online and offline (Gil de Zuniga, Jung, \& Valenzuela, 2012). Social capital, in this context, is the pool of resources an individual can take from to work towards “collective endeavors, including participation in civic and political groups” (Gil de Zuniga et al., 2012). In the end, it was concluded that using social media to gather news had a positive and significant impact on all four of the dependent variables. With the statistical relationship between social media use and an increase in social capital, people can feel more empowered and informed to participate in political activities.

\section{Graphic Imagery and Events}

The key concept that sets the current study apart from previous research is the incorporation of graphic images and events. The descriptor of 'graphic' implies explicit 
details, whether through words or pictures/videos, that can be violent, sexual, or related to content that isn’t appropriate for all consumers (e.g. children). Although what is considered to be graphic is subjective, in general, being exposed to graphic events can influence the way the individual thinks and acts in the future. Due to the nature of incidental exposure on social media, people are more likely to interact with graphic material and imagery on a more consistent basis. The people who share videos of fights or articles about wars know that they will inherently be clicked on and shared more frequently because negative information and graphic content has a much bigger draw to individuals than positive content.

In 2017, authors Grizzard et al exposed participants of their study to videos showing high, medium, low, and no levels of violence related to ISIS attacks. Participants who were exposed to higher levels of violence in the videos they were shown subsequently displayed higher levels of moral sensitivity, desires for anti-ISIS interventions (both military and humanitarian), and eudaimonia motivations (Grizzard et al). A major conclusion of this experiment is that there is a change that occurs in participants depending on the level of violence (or graphic material) they are exposed to. Traditional media outlets tend to 'sanitize' graphic material in order to avoid the potential antisocial effects exposure can have. However, this piece has supporting evidence that there are also potential prosocial effects, like pushing for action in solving humanitarian issues, that exposure to graphic material can elicit.

Graphic images and videos can’t always be shown on different platforms, but reading about graphic events also produce action. In 2015, Bonilla and Rosa dove into the idea of "hashtag activism”. Although they are numerous, the specific incidents involving 
the police and African Americans that caused the spark of this type of activism included the killings of Michael Brown, Eric Garner, and Trayvon Martin. The ability to instantly spread information on social media became the catalyst for many in-person and online protests. The hashtag ““\#Ferguson” appeared more than eight million times on the Twitter platform” within a month of the incident (Bonilla \& Rosa, 2015). The information on these killings spread so quickly and were able to reach people like never before, that entire movements like Black Lives Matter were thrusted into the spotlight all over the country and the world. Whether it was retweets of images or sharing eye-witness testimonies of the events, the culture of hashtag activism brought people together, physically and online, and inspired the creation of and gave support to multiple social and political movements.

\section{Police Interactions and Brutality}

Looking at this concept through a police interaction and brutality lenses can bring an interesting perspective to the conversation. Weaver and Lerman, in 2010, wanted to look at the relationship between contact with the criminal justice system and political participation, as well as perceived trust in the government. The most common interactions citizens have with the criminal justice system is with police officers, whether through simple traffic stops or in more severe cases like incarceration. Because of this, the police are typically considered the most visible extension of the government and interactions with them can be used to gauge attitudes towards the government as a whole. Even if a specific incident someone had with an officer was deemed to be handled fairly, it "still led to negative views of the police" (Weave \& Lerman, 2010). These types of negative interactions, along with being exposed to incidents involving derogatory 
remarks and bodily contact with the police, led to an increase in distrust in the government.

Interestingly, interactions with the police actually led to a decrease in willingness to participate in politics. Participants indicated that police encounters made them much less likely to think it was "important to vote, serve on a jury, volunteer time to community service, or serve in the military” (Weaver \& Lerman, 2010). Although this may seem counterintuitive, experiences individuals had with the police, combined with the lower overall perceived trust in the government, make people feel like the government does not care about them, so it does not make sense to expend energy participating in politics. If people don't trust the government, then they won't have confidence in the services the government can provide, whether positive or negative.

Weaver and Lerman focused on in-person interactions with the police, but in today's world of social media, many people have digital interactions with the police, and specifically, incidents of police brutality. A study from 2020 looked at how engagement with videos of the police killing unarmed Black men and boys affected college students' perceptions of the police and the issue of police violence (Campbell \& Valera, 2020). Participants, who were students of color ages 18-24, answered questions about things like how they typically find out about incidents of police violence and if they had ever been stopped by the police. Participants, $85 \%$ of which reported that they first hear about police brutality incidents through social media, displayed signs of post-traumatic stress disorder in reference to watching videos of police violence and expressed anxiety with their own interactions with police (Campbell \& Valera, 2020). Despite these students not witnessing police brutality in-person, they were still affected in ways that are consistent 
with physical and psychological trauma, which can have consequences for their future beliefs and behaviors.

The above literature hits on incidental exposure, social media use, graphic imagery, and the context of police brutality individually, and provides evidence that these factors have implications on human behaviors and attitudes. However, the past research is lacking in examinations of the concepts interacting together at the same time. Through the lens of police brutality, the current study aims to investigate the potential relationship between these factors through two hypotheses:

$\mathbf{H}_{1}$ : Individuals who are incidentally exposed to a graphic police brutality event will be more likely to participate in politics than individuals who are traditionally exposed to the event.

$\mathbf{H}_{2}$ : Individuals who are incidentally exposed to a graphic police brutality event will have lower perceived trust in the government than individuals who are traditionally exposed to the event.

These potential relationships are the premise of the current study because as Weaver and Lerman (2010) discussed, the police are the most visible and interacted-with extension of the government as a whole. They act as agents of the state and carry out the policies and procedures that the government decides to create. The prediction that being incidentally exposed to a police brutality event will increase likeliness to participate in politics is due to anecdotal examples of the aftermath of police brutality events in the United States. Typically, protests against the police, as well as the government, increase rapidly after the news of the police brutalizing another person of color is shared. The prediction that being incidentally exposed to a police brutality event will decrease 
perceived trust in the government is due to the fact that if a person is witnessing

something that the police is doing that is wrong, it is likely that they will associate those actions as what the government as a whole wants. 


\section{METHODS}

My randomized, post-test only designed experiment is based on responses from a survey created utilizing Qualtrics and Amazon’s Mechanical Turk (MTurk) services. The only Mturk workers who had the ability to choose this study were United States citizens who were at least eighteen years old. Potential participants were given instructions for the survey and information on risks and compensation for the study. Those who decided to participate were compensated $\$ 0.20$ for their time.

The first half of the survey focused on gathering demographic information, social media usage, and feelings on specific groups of people. Participants were asked about their partisanship, socioeconomic status, race/ethnicity, gender, religious affiliation, age, and political ideology. After these questions, the survey moved onto measures of social media use. Different social media platforms and quantity of time used per day were identified, and then participants responded to statements such as "I use social media to connect with friends and family" and "Social media is the first place where I am exposed to current events” (Five-point scale: Strongly Disagree-Strongly Agree). The final part of this section focused on participants' feelings towards eight different political or social groups, such as democrats, immigrants, and Black Lives Matter through the use of a feeling thermometer (scale of 0-100). Scores on the lower side of the scale indicate feeling “colder” or not as favorable towards that group and scores on the higher side indicate feeling "warmer” or more favorable. Since the treatment component of this study 
involves the police and police brutality, this measure is important to include because it allowed more control for potential bias by identifying individuals who feel very extreme about groups like Black Lives Matter (BLM). See Appendix A for specific wording of survey questions.

After these blocks of questions, participants were randomly assigned to one of two conditions. The first condition is the incidental exposure condition (IEC) and it consisted of a video of police brutality. This condition represents the scenario of a person using social media and coming across a graphic video that is being live streamed, therefore accidently being exposed to it. Participants in this group were told to watch the video, which consisted of a one-minute-long video involving the arrest and attack of an African American teenage male by two police officers. The audio of the video is a combination of the police officers yelling at the male, and the witnesses screaming to “leave him alone”. This video was filmed on a cell phone, which gives it the feeling that it could be seen on social media.

The second condition is the traditional exposure condition (TEC) using a fictional news article about an event involving police brutality. This condition represents the scenario of a person using social media and coming across a shared article from a news organization. Participants in this group were told to read a brief article. For continuity’s sake, the article was written to match up with the video that the IEC watched. The incident used in the video and article is not a recognizable case of police brutality and was initially found on YouTube. There was no identifying information associated with the video that was able to inform about the location, names of the victim or police, and 
date that the event took place. This choice was made in order to control for potential preconceived opinions and create anonymity about the case.

A control group was also included in this study. This group was told to read a brief article and then were given an unrelated article from Associated Press News about the ruins of Pompeii. The article was roughly around the same length as the article used in the TEC. Respondents in this group, as well as both treatments, were prevented from moving on to the next page until they had spent a minimum of one minute with the video or article. See Appendix B for the full articles and a link to the video.

The final part of the survey included three randomized measures for the dependent variables. These blocks were randomized to help control for any kind of bias that could have occurred if the blocks were all presented in the same order. One of these blocks contained questions on political participation. Some forms of participation listed included contacting representatives and signing petitions online or in person. Participants were asked first about participation in the past 12 months, and then about their likeliness to participate in the next twelve months (five-point scale: Very Unlikely-Very Likely).

Participants were given two different measures to gauge their trust in the government. One measure involved being asked to consider their local, state, and federal government separately and responding to statements such as "My elected officials care about what individuals want" and "People like me have a say in the government” (fivepoint scale: Strongly Disagree-Strongly Agree). This was partially adapted from the US National Election Study measure of trust from 1958.

The other measure of trust in the government focused on specific agencies at the local and state levels. Participants were asked to respond to statements such as "I feel like 
this agency serves the public well”, while keeping in mind the departments of public works, transportation, police, education, and health at the local and state level (five-point scale: Strongly Agree-Strongly Disagree). It is important to investigate more specific facets of the government with this measure because the event used directly involves the police and strong feelings about the government could be evoked with either of the conditions. See Appendix A for specific wording of survey questions.

After completing the survey, the purpose of the study was revealed to participants and they were given a validation code for compensation from Mturk. Safeguards were put into place to in order to ensure the highest validity for my project. Amazon requires the workers who can participate in surveys to be verified beforehand. Additionally, respondents were given a multiple-choice question asking them to select the response saying, "I'm not a robot" at the beginning of the survey. Those who performed this task correctly were permitted to move onto the survey and were randomly assigned to one of the three possible conditions.

After being placed in one of the treatment groups or the control, participants also had to spend at least 60-seconds on that section before they were permitted to move on. This is to try to encourage participants to fully interact with the condition they were assigned and prevents them from being able to skip over it entirely. Finally, some answer options were reversed from the order of the answers in the previous block. If one block's answers began with "Strongly Disagree” and ended with "Strongly Agree”, then the next block would begin with "Strongly Agree” and end with "Strongly Disagree”. This last technique was implemented to make participants pay more attention to the answer choices and avoid clicking the same options all the way through the survey. 


\section{DATA}

This chapter will lay out the results of the statistical tests that were performed on the data that was collected before diving into the implications of the current study in the next chapter. Descriptive tests were conducted on both the pre-treatment measures and post-treatment measures. Bivariate regression and multivariate regression tests were used to determine what interactions exist between the two treatments and control group together, as well as against some of the pre-treatment measures. The total number of participants in this study is 1,309 . With the randomization feature for the assignment of the treatments, 430 participants were given the TEC, 432 participants were given the IEC, and 413 participants were part of the control group.

Before beginning statistical tests, all measures were rescaled to make all numerical values range from $0-1$ in order to avoid issues with misleading results and graphs. In addition to that, all measures with answer that began with the highest option were rescaled to begin with the lowest option. For example, the answer choices for level of education, which began with "Graduate Degree” and ended with "Less Than High School”, were rescaled to begin with "Less Than High School”. This was done to avoid misleading directions with the results and graphs.

Descriptive statistical tests allow for better understanding of the different characteristics of the sample population who participated in the survey. They can provide insight into what potential biases were present and also provide context for later 
regressions. The demographic information collected includes political party, education, average income, race, gender, religion, age, and political ideology. To begin, the average response for political party identification is 0.56 (leaning more democrat) with a relatively bell-shaped distribution. The average response for level of education is 0.67 (learning more college-educated) with a left-skewed distribution. The average response for level of income is 0.65 (leaning towards $\$ 50,000+$ ), and it also has a left-skewed distribution. The average response for age is 0.37 (leaning towards 18 -37 years old) with a right-skewed distribution. Finally, the average response for political ideology is 0.54 (relatively moderate) with a relatively bell-shaped distribution, although it is more leftskewed than political party identification.

Moving onto the measures of social media use, the average response for hours spent using Instagram is 0.16. The average response for hours spent on Facebook is 0.15 . The average response for hours spent on Twitter is 0.14 . The average response for hours spent on TikTok jumps up to 0.21 and the average response for hours spent on YouTube is even higher with 0.25 . All of these averages are leaning towards $0-2.99$ hours a day spent on the platforms, but TikTok and YouTube are both a little closer to 3-5.99 hours a day. All of the distributions for social media use are right-skewed. Before using the social media use data for other statistical tests, the results from the five platforms were combined into one measure in order to consolidate the analysis that was performed.

Feelings towards eight different groups were measured with feeling thermometers, but due to the nature of the current study, only data from the feelings toward Republicans, Democrats, and Black Lives Matter measures were utilized. The average response for feelings towards Republicans is 0.41 (slightly unfavorable) with a 
right-skewed distribution. The average response for feelings towards Democrats is 0.53 (slightly favorable) and the distribution does not seem to follow an exact pattern. The average response for feelings towards Black Lives Matter is 0.56 (favorable) with a Ushaped distribution.

Because they are categorical, the measures on race, gender identity, and religious affiliation were not tested for average responses. With race, $71.1 \%$ of respondents identified as White, 10.9\% identified as Black, 9.1\% identified as Asian, 5.5\% identified as Latino, and 2.3\% identified as other. With gender identity, 54.9\% of respondents identified as male, $43.2 \%$ identified as female, and less than $1 \%$ identified as non-binary. With religious affiliation, 22.2\% of respondents identified as Protestant, 29.1\% identified as Catholic, $19.4 \%$ identified as a non-Christian religion or "other", and 28.1\% identified as non-religious. Visual depictions of the distributions of each variable discussed thus far can be found in Appendix C. Mean responses for each variable, along with T-test results at a 95\% confidence level, can be found below in Table 1.

Before moving on to the regression models, each of the measures for the dependent variables were combined into singular groups. Likeliness of participating in politics in the future consists of 8 individual parts, ranging from likeliness to vote to participate in a political event. When combined, the average response for the entire sample of the survey was 0.44 . To help measure reliability, Cronbach's alpha was calculated for this measure at 0.8928 , which implies that the individual measures have high internal consistency when combined.

Perceived trust in the government was split into two separate measures: one testing trust with the police and the other testing trust in local, state, and federal 


\begin{tabular}{|r|c|c|}
\hline & & t.test (conf. level =0.95) \\
\hline Party Identification & 0.56 & $0.55-0.58$ \\
\hline Education & 0.67 & $0.66-0.68$ \\
\hline Income & 0.65 & $0.63-0.66$ \\
\hline Age & 0.37 & $0.35-0.39$ \\
\hline Ideology & 0.54 & $0.53-0.56$ \\
\hline Instagram Usage & 0.16 & $0.14-0.17$ \\
\hline Facebook Usage & 0.15 & $0.14-0.17$ \\
\hline Twitter Usage & 0.14 & $0.12-0.16$ \\
\hline TikTok Usage & 0.21 & $0.19-0.24$ \\
\hline YouTube Usage & 0.25 & $0.23-0.27$ \\
\hline Republican Thermometer & 0.41 & $0.39-0.42$ \\
\hline Democrat Thermometer & 0.53 & $0.52-0.55$ \\
\hline BLM Thermometer & 0.56 & $0.54-0.58$ \\
\hline
\end{tabular}

Table 1: Mean responses for demographic information, social media usage by platform, and feeling thermometers. T-test results indicate the range of the true mean of the population at a 95\% confidence level.

governments. Because the current study uses a police brutality incident in the treatments, it was important to gauge feelings towards the police in order to see how that perception changes across conditions. Feelings towards five different agencies of the government were measured in order to avoid bias that would come with only asking questions about the police. Trust in the police consists of 3 individual parts, ranging from satisfaction with the police to wanting to make changes to the way things are done with the police. When combined, the average response for the entire sample of the survey was 0.46 . To help measure reliability, Cronbach's alpha was calculated for this measure at 0.7949 , which implies that the individual measures have high internal consistency when combined. 
Finally, trust in the local, state, and federal governments were measured separately. Each measure consisted of seven individual parts, ranging from the people who work in the government having good intentions to the government working hard to protect its people. When results from the local, state, and federal measures were combined, the average response for the entire sample of the survey was 0.50 . To help measure reliability, Cronbach’s alpha was calculated for this measure at 0.9341 , which implies that the individual measures have high internal consistency when combined. Mean responses for each combined dependent variable, along with T-test results at a 95\% confidence level, can be found below in Table 2.

\begin{tabular}{|r|c|c|}
\hline & Mean & t.test (conf. level =0.95) \\
\hline Future Political Participation & 0.44 & $0.43-0.45$ \\
\hline Trust in the Police & 0.46 & $0.45-0.48$ \\
\hline Trust in the Government & 0.50 & $0.49-0.51$ \\
\hline
\end{tabular}

Table 2: Mean responses for combined measures of the dependent variables: political participation and perceived trust in the government (two measures). T-test results indicate the range of the true mean of the population at a $95 \%$ confidence level.

As already stated, bivariate regression and multivariate regression tests were performed on the data. Before that could happen, the treatment variables needed to be separated in order to compare the results. To get a full picture of the potential impacts of the treatments, all regression models were run three times: TEC vs. Control, IEC vs. Control, and IEC vs. TEC. This thoroughness helps to ensure that all results can be presented for the analysis. With linear regression models, the null hypothesis being tested is that the true coefficient is equal to zero, or that there is no effect between the variables. If the null hypothesis is rejected, that means there is evidence that an effect between the variables exists. This is indicated by a significant p-value of less than 0.05 , which is the 
standard value for social science experiments. If the p-value is greater than 0.05 , then we fail to reject the null hypothesis.

Beginning with likeliness to participate in politics, neither the TEC or IEC against the control, or the IEC against the TEC, produced any significant results. This means that the changes that are observed between the three groups are not significant enough to be attributed to the treatments alone. Therefore, we fail to reject the null hypotheses for these three models.

Two of the three bivariate regressions with trust in the police produced significant results. The TEC vs control model has an estimated coefficient of -0.04 (p-value: 0.032), which means that the average difference in trust in the police between the control and TEC is 0.04 . The IEC vs control model has an estimated coefficient of -0.07 (p-value: 0.0001), which means that the average difference in trust in the police between the control and IEC is 0.07 . For both of these models, the null hypothesis is rejected. The model for IEC vs TEC did not yield significant results, so we fail to reject the null hypothesis.

Like the previous measure, two of the three regression models with trust in the government produced significant results. The IEC vs control model has an estimated coefficient of -0.04 (p-value: 0.01 ), which means that the average difference in trust in the government between the control and IEC is 0.04 . The IEC vs TEC model has an estimated coefficient of -0.04 (p-value: 0.008), which means that the average difference in trust in the government between the TEC and IEC is 0.04 . For both of these models, the null hypothesis is rejected. The model for TEC vs control did not yield significant results, so we fail to reject the null hypothesis. See Table 3 below for a full comparison of 
each dependent variable model with the estimated coefficient, standard error, and Pvalue.

\begin{tabular}{|r|c|c|c|}
\hline & Est. Coefficient & Std. Error & P-Value \\
\hline Political Participation & & & 0.96 \\
\hline Traditional vs Control & 0.02 & 0.017 & 0.66 \\
\hline Incidental vs Control & 0.007 & 0.017 & 0.59 \\
\hline Incidental vs Traditional & -0.009 & 0.017 & \\
\hline & & & $\mathbf{0 . 0 3 2}^{*}$ \\
\hline Trust in the Police & & & $0.0001^{* *}$ \\
\hline Traditional vs Control & $\mathbf{- 0 . 0 4}$ & 0.017 & 0.07 \\
\hline Incidental vs Control & $\mathbf{- 0 . 0 7}$ & 0.017 & \\
\hline Incidental vs Traditional & $\mathbf{- 0 . 0 3}$ & & 0.93 \\
\hline Trust in the Government & & & $\mathbf{0 . 0 1}$ \\
\hline Traditional vs Control & 0.001 & 0.015 & $\mathbf{0 . 0 0 8} * *$ \\
\hline Incidental vs Control & $\mathbf{- 0 . 0 4}$ & 0.016 & 0.016 \\
\hline Incidental vs Traditional & $\mathbf{- 0 . 0 4}$ & & \\
\hline
\end{tabular}

Table 3: Bivariate regression results for dependent variables: political participation and perceived trust in the government. P-values $<0.05$ are considered significant values.

The next statistical tests that were performed were multivariate linear regression models. Again, these regressions were run three times to encompass all potential effects of the treatments. In order to observe the effects of the treatments on non-people of color, the variable of race was subset into only participants who identified as white for these tests. The reasoning behind this is that it is a well-known conjecture that people of color tend to already have less trust in the police and government as a whole when compared to non-people of color. Results that were significant for the different controls can be interpreted as the specific variables that have some kind of impact on the dependent variables when holding all other controls constant.

To begin with political participation and the TEC vs. control, this regression model showed the average difference in willingness to participate in political activities when moving from the control group to the traditional. The models for level of education, 
social media usage, and feelings towards BLM produced significant results. An increase in education is associated with a 0.19 unit increase in political participation for the TEC. An increase in social media usage is associated with a 0.32 unit increase in political participation for the TEC. Finally, an increase in feelings towards BLM is associated with a 0.15 unit increase in political participation for the TEC. All other models for this specific group did not produce significant results, therefore we reject the null hypotheses for these cases.

With trust in the police and the TEC vs. control, this regression model showed the average difference in trust in the police when moving from the control group to the traditional. The models for political identification, religion, age, social media usage, and feelings towards BLM produced significant results. An increase in party identification is associated with a 0.12 unit decrease in trust for the TEC. An increase in religion is associated with a 0.10 unit decrease in trust for the TEC. An increase in age is associated with a 0.10 unit increase in trust for the TEC. An increase in social media use is associated with a 0.13 unit increase in trust for the TEC. Finally, an increase in feelings towards BLM is associated with a 0.11 unit decrease in trust for the TEC. All other models for this specific group did not produce significant results, therefore we reject the null hypotheses for these cases.

Lastly, with trust in the government and the TEC vs. control, this regression model showed the average difference in trust in the government as a whole when moving from the control group to the traditional. The models for education, income, religion, social media use, and feelings towards BLM produced significant results. An increase in education is associated with a 0.23 unit increase in trust for the TEC. An increase in 
income is associated with a 0.09 unit decrease in trust for the TEC. An increase in religion is associated with a 0.10 unit decrease in trust for the TEC. An increase in social media use is associated with a 0.19 unit increase in trust for the TEC. Finally, an increase in feelings towards BLM is associated with a 0.09 unit increase in trust for the TEC. All other models for this specific group did not produce significant results, therefore we reject the null hypotheses for these cases. See Table 4 below for a full comparison of each TEC v. control model against all of the controls with the estimated coefficient and

\begin{tabular}{|c|c|c|c|}
\hline & $\begin{array}{l}\text { Political Participation } \\
\text { Traditional vs Control }\end{array}$ & $\begin{array}{l}\text { Trust in the Police } \\
\text { Traditional vs Control }\end{array}$ & $\begin{array}{l}\text { Trust in the Government } \\
\text { Traditional vs Control }\end{array}$ \\
\hline \multirow[t]{2}{*}{ Treatment Effects } & -0.03 & -0.002 & -0.004 \\
\hline & 0.27 & 0.92 & 0.87 \\
\hline \multirow[t]{2}{*}{ Party Identification } & 0.07 & -0.12 & 0.001 \\
\hline & 0.15 & $0.01 *$ & 0.97 \\
\hline \multirow[t]{2}{*}{ Education } & 0.19 & 0.07 & 0.23 \\
\hline & $0.0008 * * *$ & 0.19 & $1.15 e-05 * * *$ \\
\hline \multirow[t]{2}{*}{ Income } & 0.003 & 0.002 & -0.09 \\
\hline & 0.94 & 0.96 & $0.02 *$ \\
\hline \multirow[t]{2}{*}{ Whites } & 0.06 & 0.04 & 0.05 \\
\hline & 0.07 & 0.15 & 0.08 \\
\hline \multirow[t]{2}{*}{ Gender } & -0.06 & -0.06 & 0.03 \\
\hline & 0.26 & 0.26 & 0.49 \\
\hline \multirow[t]{2}{*}{ Religion } & -0.03 & -0.10 & -0.10 \\
\hline & 0.40 & $0.004 * *$ & $0.001 * *$ \\
\hline \multirow[t]{2}{*}{ Age } & 0.02 & 0.10 & 0.03 \\
\hline & 0.75 & $0.03^{*}$ & 0.52 \\
\hline \multirow[t]{2}{*}{ Social Media Usage } & 0.32 & 0.13 & 0.19 \\
\hline & $1.18 E-07$ & $0.03^{*}$ & $0.0007 * * *$ \\
\hline \multirow[t]{2}{*}{ BLM Thermometer } & 0.15 & -0.11 & 0.09 \\
\hline & $0.0008 * * *$ & $0.01 *$ & $0.01 *$ \\
\hline
\end{tabular}

Table 4: Multivariate regression results with TEC vs. control for dependent variables and various control variables. P-values $<0.05$ are considered significant values (Top number is estimated coefficient and bottom number is P-value - bolded numbers indicate significant results)

Moving to the IEC vs. control models, this regression showed the average difference in willingness to participate in political activities when moving from the control group to the incidental. The models for education, social media usage and feelings towards BLM produced significant results for political participation. An increase 
in education is associated with a 0.15 unit increase in political participation for the IEC. An increase in social media usage is associated with a 0.21 unit increase in political participation for the IEC. Finally, an increase in feelings towards BLM is associated with a 0.16 unit increase in political participation for the IEC. All other models for this specific group did not produce significant results, therefore we reject the null hypotheses for these cases.

With trust in the police and the IEC vs. control, this regression model showed the average difference in trust in the police when moving from the control group to the incidental. The models for party identification, education, religion, and feelings towards BLM produced significant results. An increase in party identification is associated with a 0.09 unit decrease in trust for the IEC. An increase in education is associated with a 0.12 unit increase in trust for the IEC. An increase in religion is associated with a 0.01 unit decrease in trust for the IEC. Finally, an increase in feelings towards BLM is associated with a 0.16 unit decrease in trust for the IEC. All other models for this specific group did not produce significant results, therefore we reject the null hypotheses for these cases.

Lastly, with trust in the government and the IEC vs. control, this regression model showed the average difference in trust in the government as a whole when moving from the control group to the incidental. The models for education, income, religion, social media use, and feelings towards BLM produced significant results. An increase in education is associated with a 0.19 unit increase in trust for the IEC. An increase in income is associated with a 0.10 unit decrease in trust for the IEC. An increase in religion is associated with a 0.15 unit decrease in trust for the IEC. An increase in social media use is associated with a 0.11 unit increase in trust for the IEC. Finally, an increase in 
feelings towards BLM is associated with a 0.13 unit increase in trust for the IEC. All other models for this specific group did not produce significant results, therefore we reject the null hypotheses for these cases. See Table 5 below for a full comparison of each IEC v. control model against all of the control with the estimated coefficient and Pvalue.

\begin{tabular}{|c|c|c|}
\hline Political Participation & Trust in the Police & Trust in the Government \\
\hline Incidental vs Control & Incidental vs Control & Incidental vs Control \\
\hline-0.03 & -0.04 & -0.04 \\
\hline 0.32 & 0.07 & 0.09 \\
\hline 0.05 & -0.09 & 0.02 \\
\hline 0.33 & $0.03 *$ & 0.64 \\
\hline 0.15 & 0.12 & 0.19 \\
\hline $0.01 *$ & $0.03 *$ & $0.0004 * * *$ \\
\hline-0.04 & 0.01 & -0.10 \\
\hline 0.41 & 0.83 & $0.01 *$ \\
\hline 0.002 & -0.005 & 0.01 \\
\hline 0.96 & 0.85 & 0.67 \\
\hline-0.04 & -0.02 & 0.07 \\
\hline 0.50 & 0.75 & 0.10 \\
\hline-0.06 & -0.011 & -0.15 \\
\hline 0.10 & $0.0004 * * *$ & $2.48 e-06^{* * *}$ \\
\hline-0.02 & 0.06 & 0.07 \\
\hline 0.67 & 0.18 & 0.10 \\
\hline 0.21 & 0.05 & 0.11 \\
\hline $0.0002 * * *$ & 0.30 & $0.02 *$ \\
\hline 0.16 & -0.16 & 0.13 \\
\hline $0.0004 * *$ & $6.68 e-05 * * *$ & $0.001 * *$ \\
\hline
\end{tabular}

Table 5: Multivariate regression results with IEC vs. control for dependent variables and various control variables. P-values $<0.05$ are considered significant values (Top number is estimated coefficient and bottom number is P-value - bolded numbers indicate significant results)

Finally, moving to the IEC vs. TEC models, this regression showed the average difference in willingness to participate in political activities when moving from the traditional treatment to the incidental. The models for education, social media use and feelings towards BLM produced significant results for political participation. An increase in education is associated with a 0.13 unit increase in political participation for the IEC. An increase in social media usage is associated with a 0.34 unit increase in political 
participation for the IEC. An increase in feelings towards BLM is associated with a 0.12 unit increase in political participation for the IEC. All other models for this specific group did not produce significant results, therefore we reject the null hypotheses for these cases. With trust in the police and the IEC vs. TEC, this regression model showed the average difference in trust in the police when moving from the traditional treatment to the incidental. The models for treatment effect, party identification, age, social media use, and feelings towards BLM produced significant results. A significant result for the treatment effect in this model means that with holding everything else constant, the average difference between trust in the police for the TEC to the IEC decreases by 0.05 units. An increase in party identification is associated with a 0.09 unit decrease in trust in the IEC. An in age is associated with a 0.18 unit increase in trust in the IEC. An increase in social media usage is associated with a 0.10 unit increase in trust for the IEC. Finally, an increase in feelings towards BLM is associated with a 0.19 unit decrease in trust for the IEC. All other models for this specific group did not produce significant results, therefore we reject the null hypotheses for these cases.

Lastly, with trust in the government and the IEC vs. control, this regression model showed the average difference in trust in the government as a whole when moving from the traditional treatment to the incidental. The models for education, income, religion, social media usage, and feelings towards BLM produced significant results. An increase in education is associated with a 0.16 unit increase in trust for the IEC. An increase in income is associated with a 0.11 unit decrease in trust for the IEC. An increase in religion is associated with a 0.09 unit decrease in trust for the IEC. An increase in social media usage is associated with a 0.21 unit increase in trust for the IEC. Finally, an increase in 
feelings towards BLM is associated with a 0.08 unit increase in trust for the IEC. All other models for this specific group did not produce significant results, therefore we reject the null hypotheses for these cases. See Table 6 below for a full comparison of each IEC v. TEC model against all of the control with the estimated coefficient and Pvalue.

\begin{tabular}{|c|c|c|}
\hline Political Participation & Trust in the Police & Trust in the Government \\
\hline Incidental vs Traditional & Incidental vs Traditional & Incidental vs Traditional \\
\hline-0.01 & -0.05 & -0.04 \\
\hline 0.67 & $0.05 *$ & 0.06 \\
\hline 0.07 & -0.09 & 0.01 \\
\hline 0.17 & $0.03 *$ & 0.69 \\
\hline 0.13 & 0.08 & 0.16 \\
\hline $0.02 *$ & 0.12 & $0.002 \%$ \\
\hline-0.02 & -0.01 & -0.11 \\
\hline 0.73 & 0.73 & $0.01 *$ \\
\hline 0.0006 & 0.004 & 0.03 \\
\hline 0.98 & 0.88 & 0.29 \\
\hline-0.04 & -0.04 & 0.05 \\
\hline 0.45 & 0.36 & 0.25 \\
\hline-0.05 & -0.05 & -0.09 \\
\hline 0.18 & 0.12 & $0.004 * *$ \\
\hline-0.02 & 0.18 & 0.07 \\
\hline 0.74 & $3.30 e 05 * * *$ & 0.09 \\
\hline 0.34 & 0.10 & 0.21 \\
\hline $7.24 e-09 * * *$ & $0.05 *$ & $7.30 e-05 * * *$ \\
\hline 0.12 & -0.19 & 0.08 \\
\hline $0.01 *$ & $1.02 e-05 * * *$ & $0.05 *$ \\
\hline
\end{tabular}

Table 6: Multivariate regression results with IEC vs. TEC for dependent variables and various control variables. P-values $<0.05$ are considered significant values (Top number is estimated coefficient and bottom number is P-value - bolded numbers indicate significant results)

The last part of the statistical tests that were performed on this data were scatterplots and interaction plots for the significant results from the multivariate regression. In order to consolidate the potential results to the purpose of the current study, these tests only used the IEC vs. TEC models. Scatterplots, with lines-of-best-fit that correlate with the estimated coefficient from the regression models, can help to visualize the true relationship between variables. These scatterplots were created for the different dependent and control variables that resulted in significant relationships from the 
multivariate tests. They are useful tools in examining the directional relationship the dependent variables have with different controls. Appendix $D$ has scatterplots that show the association between education, social media usage, and feelings towards BLM and likeliness to participate in politics. Appendix $E$ has scatterplots that show the association between party identification, age, social media usage, and feelings towards BLM and perceived trust in the police. Appendix $F$ has scatterplots that show the association between education, income level, religion, social media usage, and feelings towards BLM and perceived trust in the government.

An interaction test is a tool that can help to identify heterogeneous treatment effects between dependent variables and the controls. By utilizing this type of test, we can answer the question of whether or not different identifying variables effect the results of the treatments. Focusing only on the IEC vs. TEC, interaction tests were ran for each dependent variable and each control variable one at a time. Political participation only had one significant interaction with social media usage (coefficient: -0.23 , p-value: 0.04*). This means that when comparing participants who received the IEC to those who received the TEC, willingness to participate in politics was increased at a slowly rate as social media use increased.

Trust in the police only had two significant interaction with gender (coefficient: 0.14, p-value: $0.03^{*}$ ) and income (coefficient: -0.01 , p-value: $0.04^{*}$ ). This means that when comparing participants who received the IEC to those who received the TEC, trust in police was higher for females versus males. Additionally, comparing the IEC to the TEC, trust in the police increased at a slower rate as income levels increased. Lastly, trust in the government had one significant interaction with political ideology (coefficient: 
0.13, p-value: $0.009^{* *}$ ). This means that when comparing participants who received the IEC to the TEC, trust in the government increased as ideology increased. See Appendix G to see the visual representations of these significant heterogenous effects. 


\section{DISCUSSION}

The current study sought to explore the relationship between incidental exposure to police brutality and willingness to participate in politics and perceived trust in the government. The hypotheses are as follows:

H1: Individuals who are incidentally exposed to a graphic police brutality event will be more likely to participate in politics than individuals who are traditionally exposed to the event.

H2: Individuals who are incidentally exposed to a graphic police brutality event will have lower perceived trust in the government than individuals who are traditionally exposed to the event.

After analyzing the data collected through the survey, the current study finds no support

for $\mathrm{H}_{1}$ and partial support for $\mathrm{H}_{2}$. Even though there is not support for $\mathrm{H}_{1}$, there were still some significant findings related to it.

The regression models for each dependent variable were ran three times with the TEC vs. control, IEC vs. control, and IEC vs. TEC in order to gain a full picture of the data that was collected. However, for purposes of testing the hypotheses, the TEC vs. control data will not be used. This is because the current study was focused on how the incidental exposure treatment, not the traditional exposure, affected the dependent variables. 
Starting with political participation, the data shows that when comparing both treatments to the control, and also to each other, there are no significant differences. That means that participants being incidentally exposed to a graphic police brutality event did not change their willingness to participate in politics. However, when control variables are added into the regression, we begin to see where there are significant differences between the treatments. With the IEC vs. control and IEC vs. TEC, we can see significant results depending on the participants' level of education, social media usage, and feelings towards BLM. For both models, the estimated coefficients were positive values, which means that level of education, social media usage, and feelings towards BLM positively affects willingness to participate in political activities when holding all other factors constant.

Between the IEC vs. control and the IEC vs. TEC models, the control with the greatest increase is social media usage, with a difference of 0.13 . The more that participants use social media platforms, on average, the more likely they are to participant in political activities when exposed to the incidental treatment compared to the traditional and the control. When looking at the interaction models as well, social media is the only variable that has a significant interaction on political participation. With this social media measure being a prominent influence on the dependent variable, further research into its relationship should be examined.

The results provide partial support for the second hypothesis. When focusing on the treatments by themselves, the IEC vs. control measure with trust in the police produced a significant result. With trust in the government, both the IEC vs. control measure and the IEC vs. TEC measure produced significant results. All three estimated 
coefficients were negative values. This means that participants who were incidentally exposed to a police brutality event had lower overall perceived trust in the police when compared to the control group.

Separately, those who were incidentally exposed to police brutality had a lower overall perceived trust in the government as a whole when compared to the control and the TEC. This is an important finding because it supports the idea that witnessing a police brutality incident through sources like social media has a negative effect on the way those individuals think about the government. This can explain why when videos of violence against people of color by the police go viral, protestors often focus their efforts on government agencies, structures, and even property. When individuals lose trust in the government, it not only makes the government less effective, but threatens the integrity of democracy as a whole.

When adding the various controls into the regression models with trust in the police and the government, there are significant results that show party identification, social media usage, and feelings towards BLM, and effect trust in different ways. With perceived trust in the police, the estimated coefficients with party identification and feelings towards BLM for both IEC vs. control and IEC vs. TEC were all negative values. This means that as party identification becomes more liberal and feelings towards BLM become more favorable, perceived trust in the police decreases when exposed to the incidental treatment compared to the control and traditional treatment. The estimated coefficient for social media usage was only significant for the IEC vs TEC model, and it was actually a positive value. That means that the more participants use social media 
platforms, on average, the higher their perceived trust of the police is when exposed to the incidental treatment compared to the traditional.

With perceived trust in the government as a whole, the estimated coefficients for social media usage and feelings towards BLM for both IEC vs. control and IEC vs. TEC were all positive values. This means that the more participants use social media platforms, and the more favorable they feel towards BLM, the higher their perceived trust of the government is when exposed to the incidental treatment compared to the control and traditional treatment. The fact that the trust in the police and trust in the government measures when compared to feelings towards BLM are inverse (one has negative effects and the other has positive effects) is significant because it shows how the treatments only further degrade the overall perceptions of the police as agent of the state.

Other control variables such as age, income, and education have relationships with trust in the police and trust in the government that are consistent with past research and are not surprising to be found as significant. The interaction models also show how gender and income for the police, and political ideology for the government, can have heterogenous effects. This means that the gender, income level, and political ideology a participant identified as had a true effect on their responses to the dependent variable measures.

One of the biggest pieces of evidence to support $\mathrm{H}_{2}$ comes from the results from the treatment effect measure in the IEC vs. TEC model with trust in the police. With all of the other variables included in the regression being held constant, the average difference in the treatment groups remained significant from the bivariate regression model where they were tested by themselves. This shows that there truly is an effect on 
trust in the police present with the phenomenon of incidental exposure to a police brutality event. It is also worth mentioning that they treatment effect measure for trust in the government as a whole within the IEC vs. TEC was only 0.01 points off of being a significant result. Although it cannot be claimed as significant, the fact that it is extremely close to the set p-value shows that there definitely is a relationship present, and it warrants further investigation.

The limitations of the current study go hand-in-hand with the direction this research could go in the future. The second hypothesis of this study was very generalized with overall trust in the government. In hindsight, this variable should have been broken up into trust in the police and trust in the government, which is what was actually tested. Perceptions of trust in the police is extremely prevalent today, and further studies should be done on the effects of public opinion on police departments. Although a little bit of insight was gained, a three-question measure to gauge an individual's whole perception of trust in the police is not nearly thorough enough, especially with the assumption that police departments are direct agents of the state. As individuals' trust in the police, and the government, declines, the threat to the country's functioning democracy rises, and this phenomenon deserves more exploration.

Even though the current study did not produce any significant result within the willingness to participate in political activity variable, if the measures were taken out of the index they were put in and analyzed separately, there could be some potential for significant results. The reasoning behind this is that certain political activities are extremely low-cost for an individual to partake in, such as signing an online petition. 
When low-cost measures like that are put together with high-cost items, like attending a protest or donating money, some of the true effects could be lost.

Another potential limitation to a study like the current one is all of the effects that this past year could have on individuals. 2020 was full of chaos and confusion, both socially and politically. The presidential election was arguably the most contentious election in the history of the United States and it seemed like anything political was surrounded by a cloud of fighting for the "fate of the country". At the same time, within a two-month period, Breonna Taylor in Kentucky and George Floyd in Minnesota were killed at the hands of the police and protests erupted around the world. Videos of the instances were not only shared rapidly on social media, but the mainstream media could not stop covering the aftermath of these events. The residual effects from the election, combined with the major police brutality events of 2020, could have created some kind of bias in the results of the current study. The fact that a police brutality incident was selected for the treatments, as opposed to a different kind of graphic event, could already have triggered participants to answer the dependent variable measures in a certain way. Future research could try to compare results of a study like the current one in a time where the news cycle is focused on something other than police brutality and politics to see if there truly are some kind of biases at work.

Incidental exposure on social media is not a phenomenon that will be going away any time soon. Although the companies that own the platforms use algorithms to tailor social media experiences to the interests of the user, it is impossible to avoid all interactions an individual might have with unwanted information. In the same breath, police brutality towards people of color, especially black people, has been happening for 
much longer than individuals realize. It is only now that it is being given the attention it deserves due to the tools of social media platforms and information-sharing capabilities. As social media becomes more integrated into people's lives, the chances of being incidentally exposed to graphic imagery, will only continue to grow. Where some people might argue that police brutality is not an issue that needs to be solved, this study shows that when people are incidentally exposed to it, as they are likely to be on social media, their perceptions of the world change. Whether they realize it or not, the degradation of public opinion on the government and police will only harm those in power, and the way to change that is to address the institutional problems that have led to the issues at hand. 


\section{REFERENCES}

Bennett, W. L. (2012). The Personalization of Politics: Political Identity, Social Media, and Changing Patterns of Participation. The ANNALS of the American Academy of Political and Social Science, 644(1), 20-39.

Bonilla, Y. and Rosa, J. (2015). \#Ferguson: Digital protest, hashtag ethnography, and the racial politics of social media in the United States. American Ethnologist, 42, 417.

Campbell, F. \& Valera, P. (2020). “The Only Thing New is the Cameras”: A Study of U.S. College Students' Perceptions of Police Violence on Social Media. Journal of Black Studies, 51(7), 654-670.

Fletcher, R., \& Nielsen, R. K. (2017). Are people incidentally exposed to news on social media? A comparative analysis. New Media \& Society, 20(7), 2450-2468.

Gil de Zúñiga, H., Jung, N., and Valenzuela, S. (2012). Social Media Use for News and Individuals' Social Capital, Civic Engagement and Political Participation. Journal of Computer-Mediated Communication, 17(3), 319-336.

Grizzard, M., Huang, J., Weiss, J. K., Novotny, E. R., Fitzgerald, K. S., Ahn, C., Ngoh, Z., Plante, A., \& Chu, H.. (2017). Graphic Violence as Moral Motivator: The Effects of Graphically Violent Content in News. Mass Communication and Society, 20(6), 763-783. 
Tewksbury, D., Weaver, A. J., \& Maddex, B. D. (2001). Accidentally Informed: Incidental News Exposure on the World Wide Web. Journalism \& Mass Communication Quarterly, 78(3), 533-554.

Weaver, V. M., \& Lerman, A. E. (2010). Political Consequences of the Carceral State. American Political Science Review, 104(4), 817-833.

Weeks, B., Lane, D., Kim, D., Lee, S., \& Kwak, N. (2017). Incidental Exposure, Selective Exposure, and Political Information Sharing: Integrating Online Exposure Patterns and Expression on Social Media. Journal of ComputerMediated Communication, 22(6), 363-379. 


\section{APPENDIX}

\section{$\underline{\text { Appendix A }}$}

\section{Demographic Survey Questions and Answer Options}

1. Political Affiliation: Which of the following best describes you? (Strong Republican, Republican, Lean Republican, Independent, Lean Democrat, Democrat, Strong Democrat)

2. SES:

a) What is your highest level of education? (Graduate Degree, Bachelor's Degree, Associates Degree, Some College, High School Diploma or GED, Less than High School or GED)

b) What would you say your household's approximate yearly income bracket is? (less than $\$ 10,000, \$ 10,000$ - \$30,000, $\$ 30,000$ - \$50,000, \$50,000$\$ 70,000, \$ 70,000$ or more).

3. Race/Ethnicity: What is your race or ethnic identity? (White, African American, Latino/ Hispanic, Asian, Other).

4. Gender: What is your gender? (Female, Male, Non-Binary)
5. Religious Affiliation: What is your religious affiliation? (Protestant, Catholic, Islamic, Jewish, Hindu, Buddhist, Other Religion, Not Affiliated)

6. Age: What is your age in years? $(18-27,28-37,38-47,48-57,58+)$

7. Political Ideology: We hear a lot of talk these days about liberals and conservatives. On a scale of one through seven, where " 1 " is very liberal and " 7 " is very conservative, where would you place yourself on this scale or haven't you thought much about it? (Very liberal, liberal, slightly liberal, moderate middle of the road, slightly conservative, conservative, very conservative, other, haven't though much about it)

\section{Social Media Use Survey Questions and Answer Options}

Think about your social media use and respond to the following:

1. What social media platforms do you use? Select all that apply. (Facebook, Instagram, Twitter, TikTok, YouTube, I don't use social media)

2. On average, how much time do you spend on social media every day? (0-2.99 hours, 3-5.99 hours, 
6-8.99 hours, 9+ hours, I don't

use this platform)

Read the following statements

and select the response that most

represents you

3. I use social media to connect with friends and family.

4. I use social media to get involved with social causes.

5. I often do my own research on news stories I see shared on social media.

6. Social media is the first place where I am exposed to current events.

7. I actively follow/like political organizations on social media.

(Answers: Strongly Disagree, Disagree, Neither Disagree/Agree, Agree, Strongly Agree)

\section{Political and Social Groups Questions and Answer Options}

Consider the following political and social groups in the United States. Select how warm or cold you feel towards them. Ratings between 0 degrees and 50 degrees mean you feel less favorable toward that group. Ratings between 50 degrees and 100 degrees mean you feel more favorable toward that group.

\section{Republicans}

Democrats

Immigrants

Feminists

Black Lives Matter

National Rifle Association

Trade Unions

Religious Organizations
(Answers: will range from 0-100)

\section{Political Participation Survey Questions and Answer Options (randomized)}

Think about different ways to participate in politics and respond to the following:

In the past 12 months, I have done the

following:

Contacted one or more of my representative

Signed a petition online

Signed a petition in person

Worked with a political group or

candidate

Donated money to a political group or candidate

Attended a political event (online OR in person)

Participated in a protest or

demonstration

Voted

(Answers: Yes, No, Unsure)

In the next 12 months, how likely are you to do the following:

Contact my representative

Sign a petition online

Sign a petition in person

Work with a political group or candidate

Donate money to a political group or candidate

Attend a political event (online OR in person)

Participate in a protest or demonstration Vote

(Answers: Very Unlikely, Unlikely, Neither Unlikely/Likely, Likely, Very Likely) 


\section{Political Trust Survey Questions and Answers (randomized)}

Think about your local, state, and federal governments and respond to the following:

Local Government:

My elected officials care about what individuals want.

The government is good at dealing with problems that arise.

The people who work in the government have good intentions.

People like me have a say in the government.

The government works hard to protect the people.

The government pays attention to the needs of the community.

I trust that the government does what's best for the people.

\section{State Government:}

My elected officials care about what individuals want.

The government is good at dealing with problems that arise.

The people who work in the government have good intentions.

People like me have a say in the government.

The government works hard to protect the people.

The government pays attention to the needs of the community.

I trust that the government does what's best for the people.

\section{Federal Government:}

My elected officials care about what individuals want.

The government is good at dealing with problems that arise.

The people who work in the government have good intentions.
People like me have a say in the government.

The government works hard to protect the people.

The government pays attention to the needs of the community.

I trust that the government does what's best for the people.

(Answers: Strongly Disagree, Disagree, Neither Disagree/Agree, Agree, Strongly Agree)

\section{Effectiveness of the Government Survey Questions and Answer Options (randomized)}

Think about the different facets of your local and state government and respond to the following:

I feel like this agency serves the public well:

Department of Public Works

Department of Police

Department of Transportation

Department of Health

Department of Education

I would change the way some things are done in this agency:

Department of Public Works

Department of Police

Department of Transportation

Department of Health

Department of Education

I am satisfied with the overall quality of work from this agency:

Department of Public Works

Department of Police

Department of Transportation

Department of Health

Department of Education 
(Answers: Strongly Agree, Agree, Neither Disagree/Agree, Disagree, Strongly Disagree) 
Appendix B

\section{Incidental Exposure Treatment}

https://drive.google.com/open?id=1jUzDDK 2HTPQRVKLHfflCseIYETDu6NHx

\section{$\underline{\text { Traditional Exposure Treatment }}$}

RICHMOND TEEN BEATEN BY COPS AND ARRESTED FOR WALKING TO THE LIBRARY WITH FRIENDS

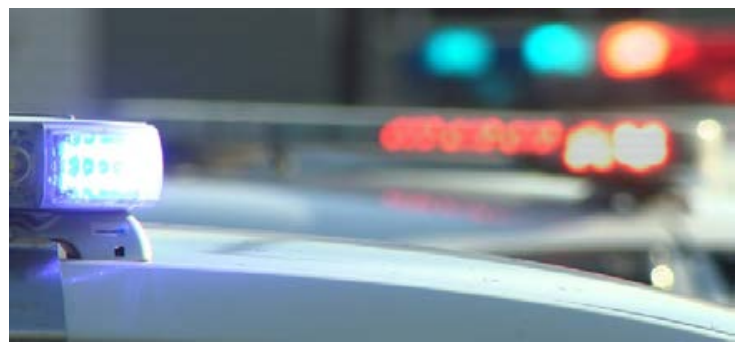

By Samantha Hill - WKYT

September 10 ${ }^{\text {th }}, 2019$ at 2:32 pm EST

RICHMOND, KENTUCKY - 18-yearold Cameron Brown has become the newest victim of police brutality in the quiet, college-town of Richmond, Kentucky.

At approximately 3:30 pm on Monday, Madison County Dispatch received a report of four "suspicious teenagers" walking through the Grey Oaks neighborhood in Richmond. The caller stated that they "didn't recognize any of the teens" and thought "they might be up to trouble".

When the Richmond Police Department arrived in the neighborhood, Brown was walking with two friends and his younger sister in the direction of Main Street. The identities of the three others are to remain anonymous due to being minors.
According to Brown, one male and one female officer, identified later as Officers Lykins and Wood, stopped their group and asked them what they were doing in the neighborhood. Brown told them that they were "walking to the Madison County Public Library for his sister to return checked out books". The officers asked again why they were in the Grey Oaks neighborhood, and Brown answered that one of the friends lived there.

"They just kept asking us why we were in that neighborhood. We were just walking from my friend's house, but it was clear those officers wanted more of an answer.” Brown stated.

According to the video taken by Brown's friend, after he refused to give the officers the friend's house address, the situation escalated. Brown was informed that he was going to need to provide the address of the house or be arrested for "not cooperating with police”.

"I know what my rights are. We weren't doing anything wrong, so I just sat down and refused to speak to them anymore" Brown told reporters.

Officer Wood attempted to put handcuffs on Brown and when he moved his hands out of the way, the officer pushed him down to the ground and tried to get him on his stomach in order to get the handcuffs on. Almost immediately, Officer Lykins jumped in and began punching Brown in the face to get him to "put his hands behind his back".

Officer Lykins was on top of Brown, and continued to hit him, for 45 seconds while Brown was face down in the grass. 
"He kept screaming for me to put my hands behind my back but he was on top of me!" Brown exclaimed "I couldn't do anything, and I was terrified they were going to shoot me, so I froze up."

Brown was arrested for resisting arrest and was taken to the Madison County Detention Center, where he was released later that night after footage of the incident was reviewed. It was reported that Brown suffered from a broken nose and multiple cuts and bruises on his arms, neck, back, and face.

"I'm happy my baby is safe, but this kind of thing happens way too much." Brown's mother told reporters. "Since when is walking from a friend's house to the library a reason to get beaten?”

The Richmond Police Department has declined to comment at this time.

\section{Control Group Article}

\section{Archeologists find intact ceremonial chariot near Pompeii}

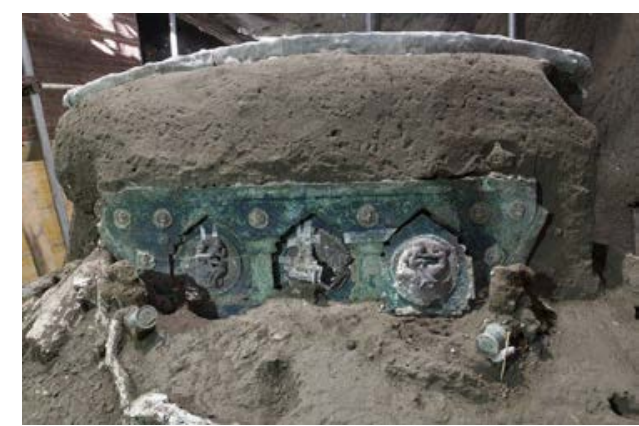

By COLLEEN BARRY February 27, 2021

MILAN (AP) — Officials at the Pompeii archaeological site in Italy announced Saturday the discovery of an intact ceremonial chariot, one of several important discoveries made in the same area outside the park near Naples following an investigation into an illegal dig.

The chariot, with its iron elements, bronze decorations and mineralized wooden remains, was found in the ruins of a settlement north of Pompeii, beyond the walls of the ancient city, parked in the portico of a stable where the remains of three horses previously were discovered.

The Archaeological Park of Pompeii called the chariot "an exceptional discovery" and said "it represents a unique find - which has no parallel in Italy thus far - in an excellent state of preservation.”

The eruption of Mount Vesuvius in 79 AD destroyed Pompeii. The chariot was spared when the walls and roof of the structure it was in collapsed, and also survived looting by modern-day antiquities thieves, who had dug tunnels through to the site, grazing but not damaging the four-wheeled cart, according to park officials.

The chariot was found on the grounds of what is one of the most significant ancient villas in the area around Vesuvius, with a panoramic view of the Mediterranean Sea. on the outskirts of the ancient Roman city.

Archaeologists last year found in the same area on the outskirts of Pompeii, Civita Giulian, the skeletal remains of what are believed to have been a wealthy man and his male slave, attempting to escape death.

The chariot's first iron element emerged on Jan. 7 from the blanket of volcanic material filling the two-story portico. 
Archaeologists believe the cart was used for festivities and parades, perhaps also to carry brides to their new homes.

While chariots for daily life or the transport of agricultural products have been previously found at Pompeii, officials said the new find is the first ceremonial chariot unearthed in its entirety.

The villa was discovered after police came across the illegal tunnels in 2017, officials said. Two people who live in the houses atop the site are currently on trial for allegedly digging more than 80 meters of tunnels at the site. 


\section{Appendix C}

Histograms for demographic information, social media usage by platform, and feeling thermometers.
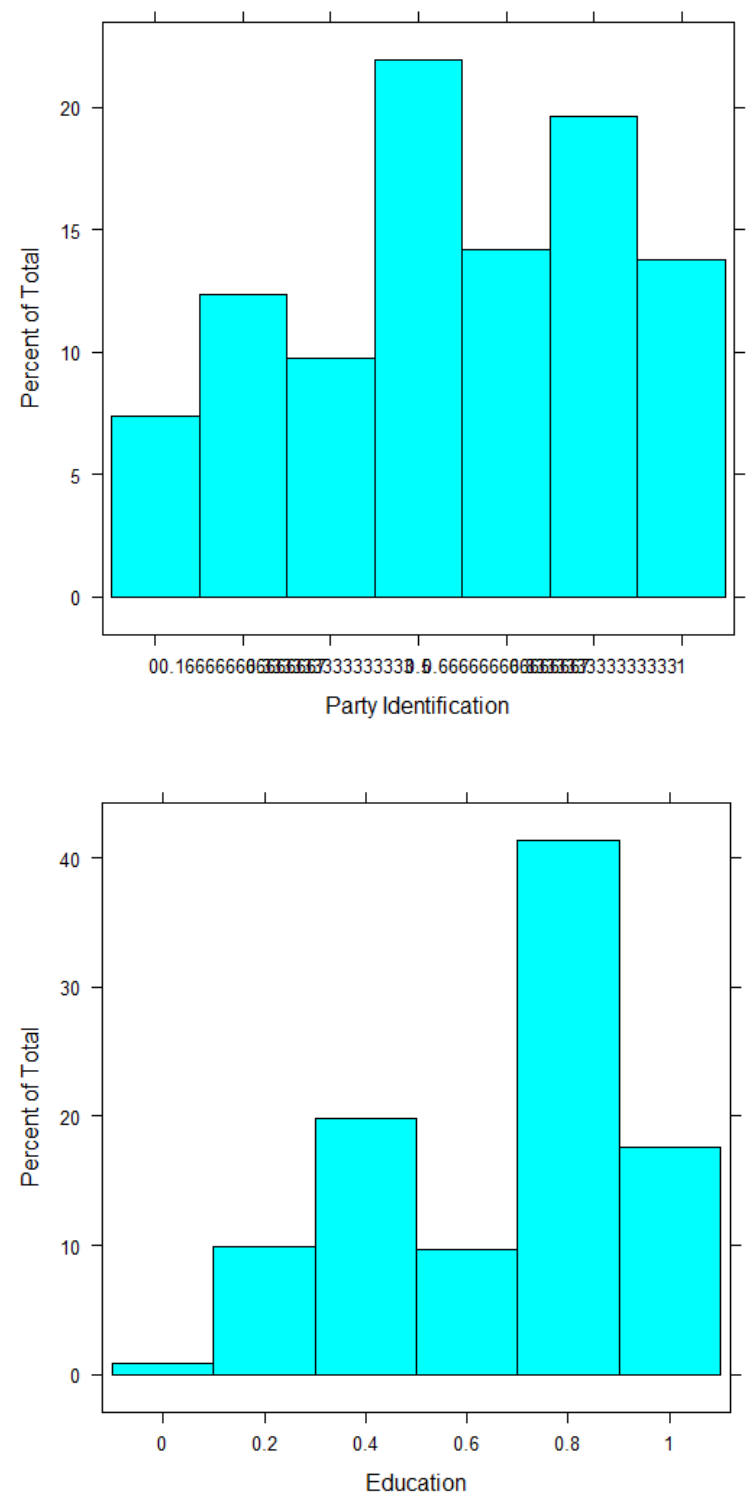
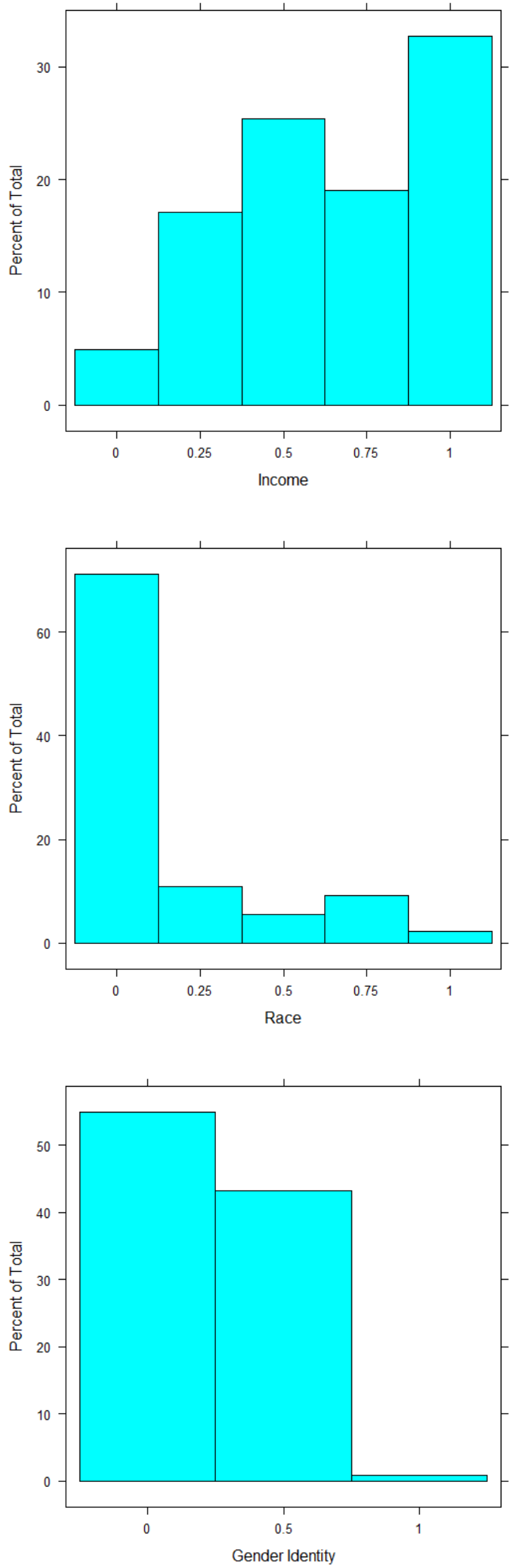


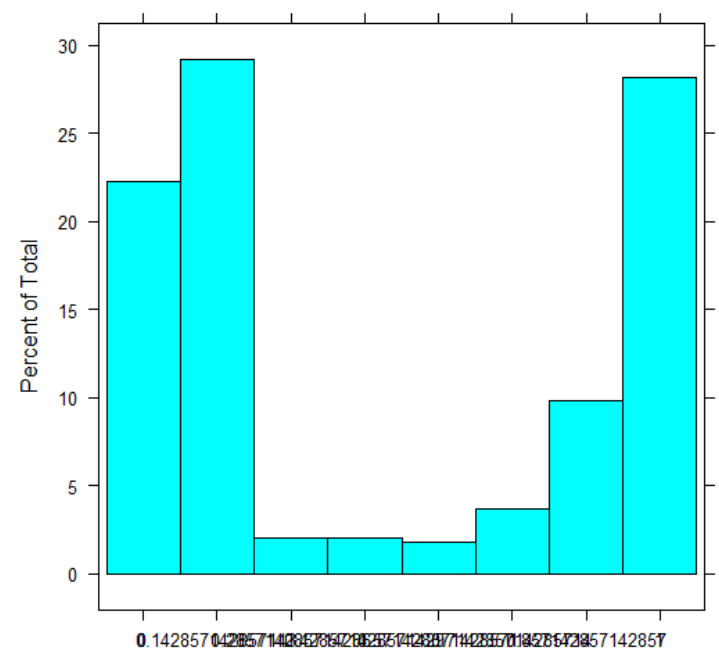

Religious Affiliation
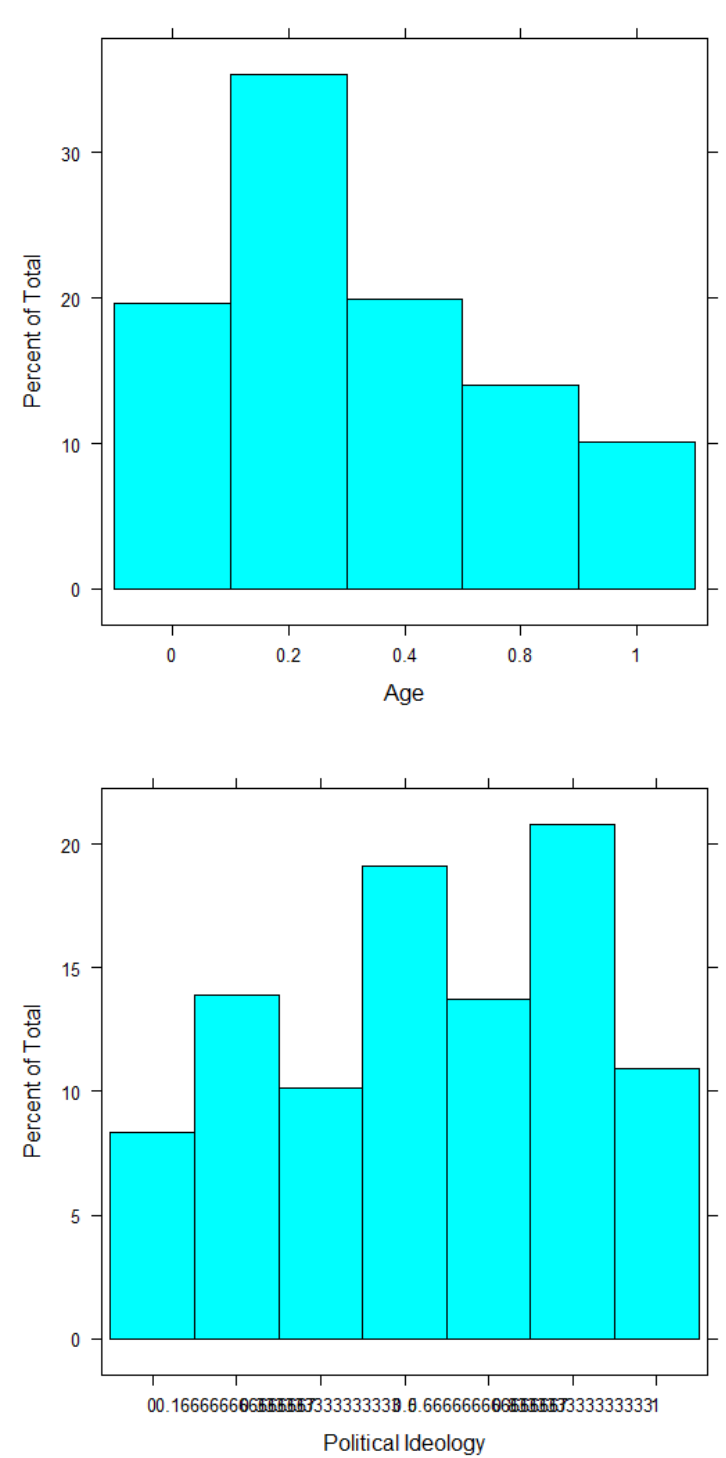
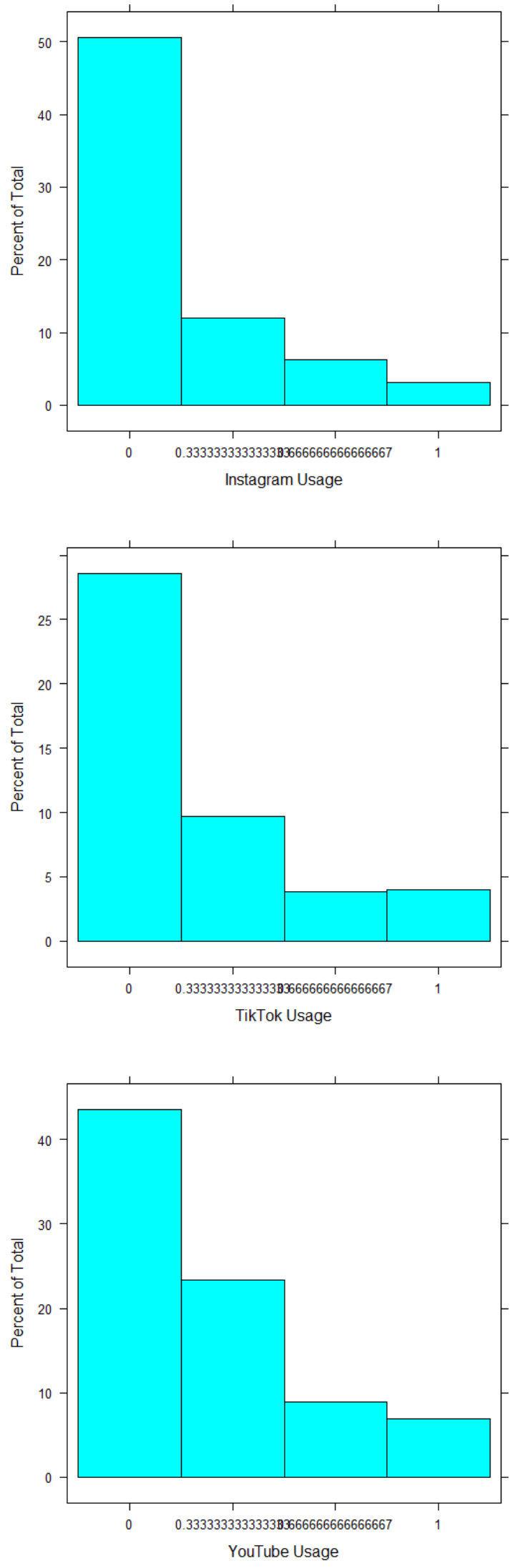

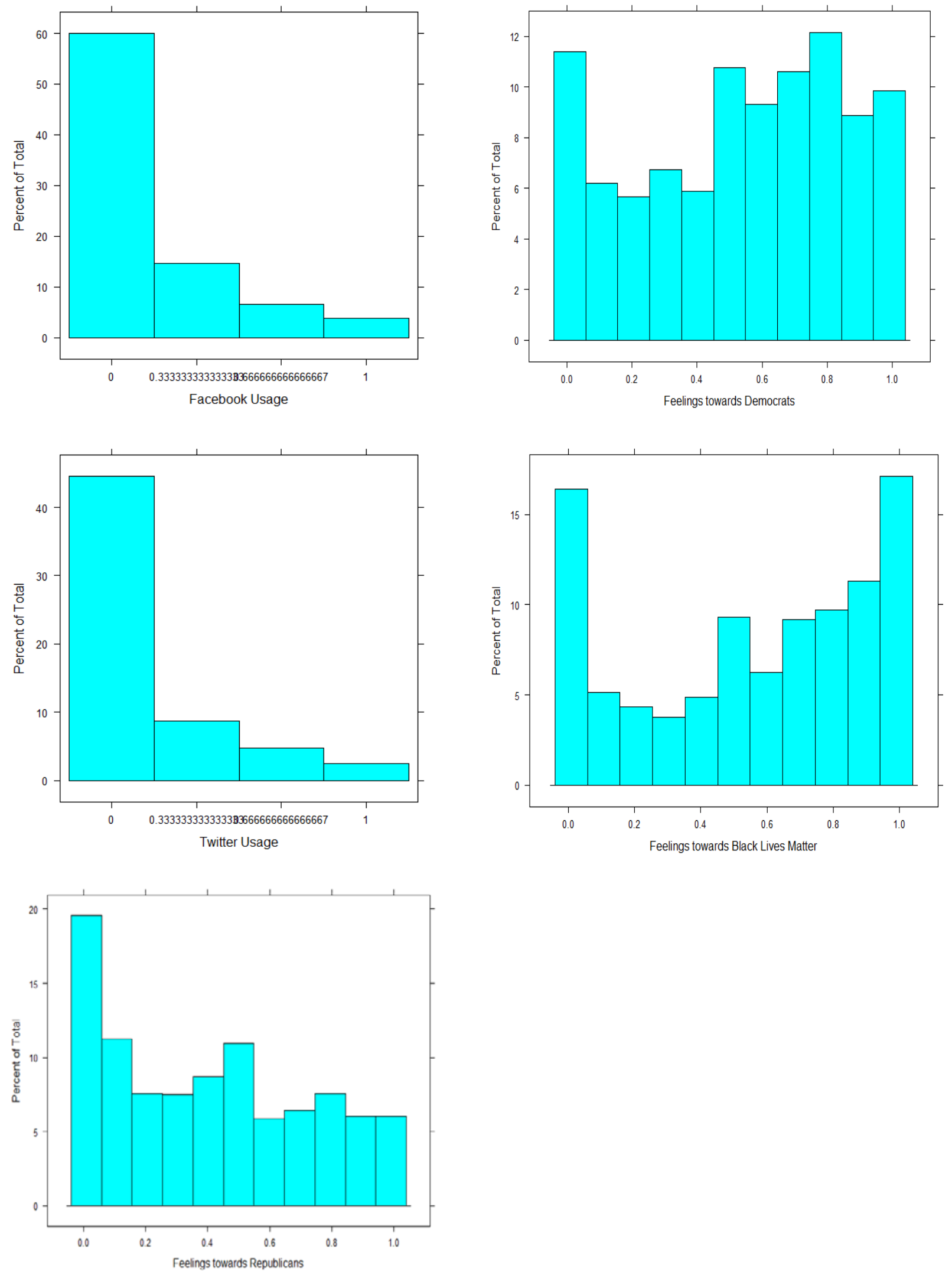


\section{Appendix D}

Scatterplots for relationship between the treatment groups with likeliness to participate in politics and demographic information (significant ${ }^{1}$ results only)
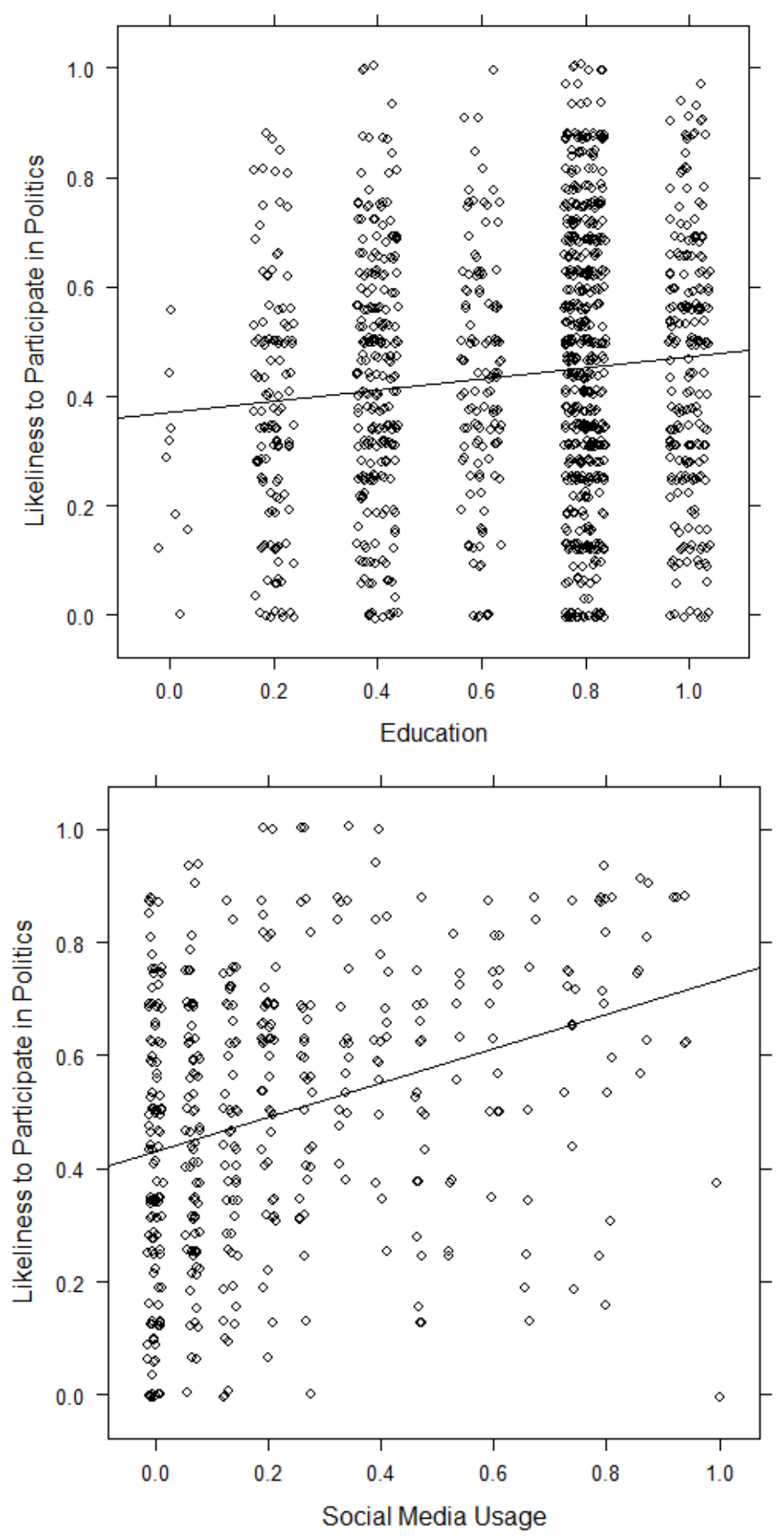

${ }^{1}$ Significant indicates a p-value of $<0.05$ after performing a multivariate regression test 


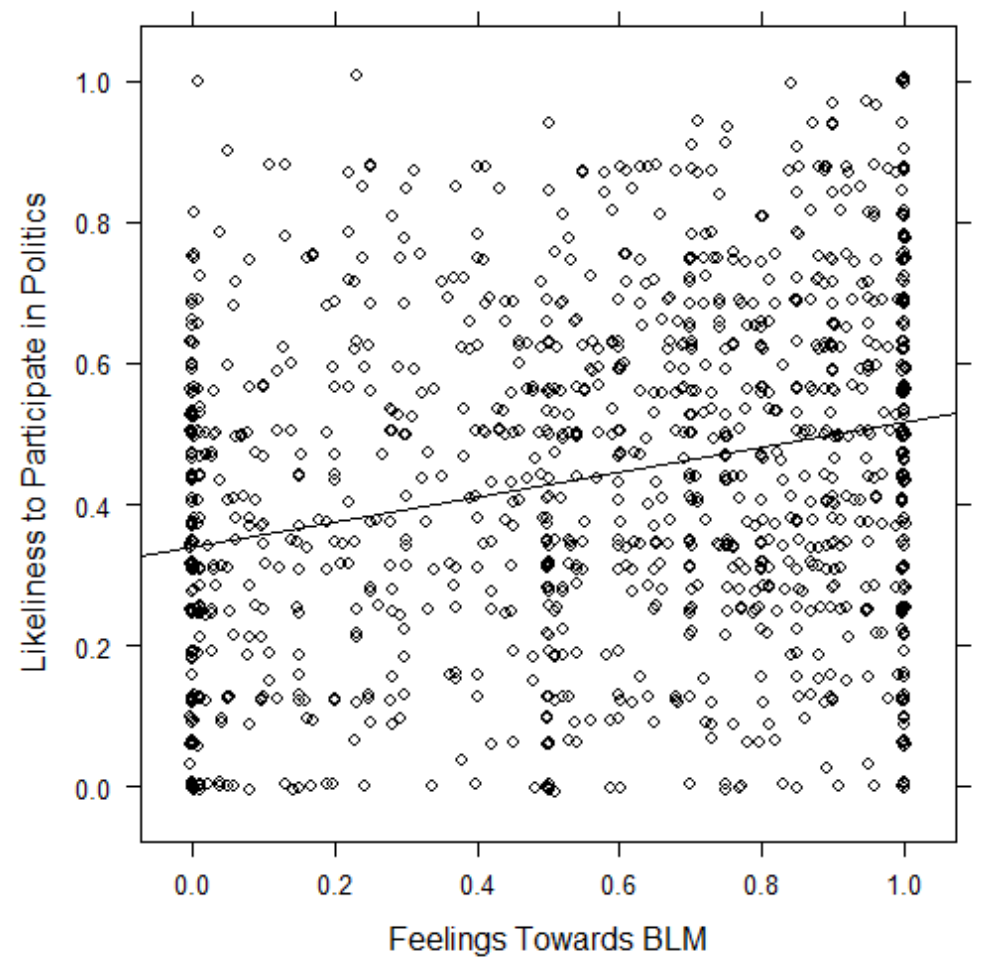




\section{Appendix E}

Scatterplots for relationship between the treatment groups with trust in the police and demographic information (significant ${ }^{2}$ results only)
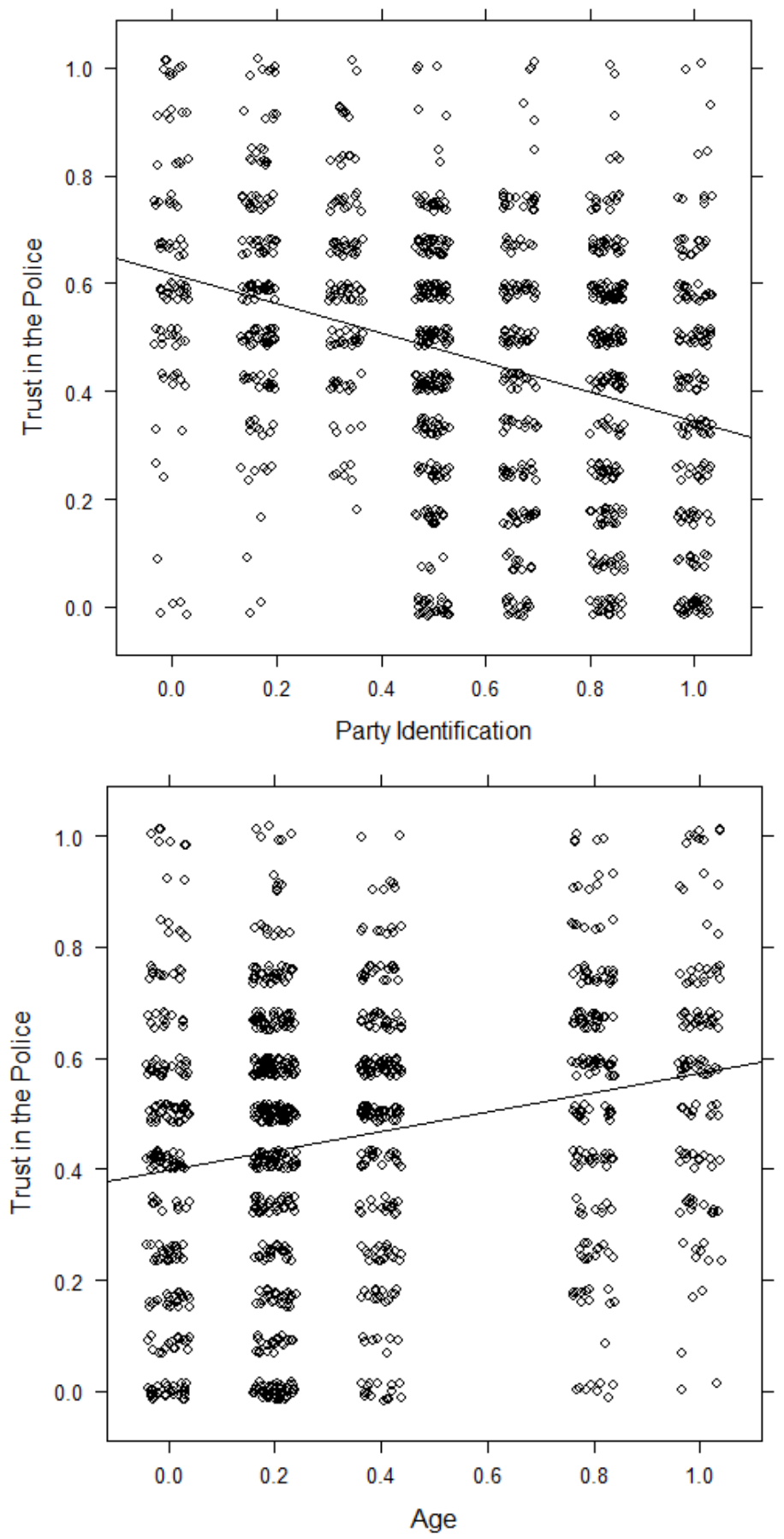

${ }^{2}$ Significant indicates a p-value of $<0.05$ after performing a multivariate regression test 

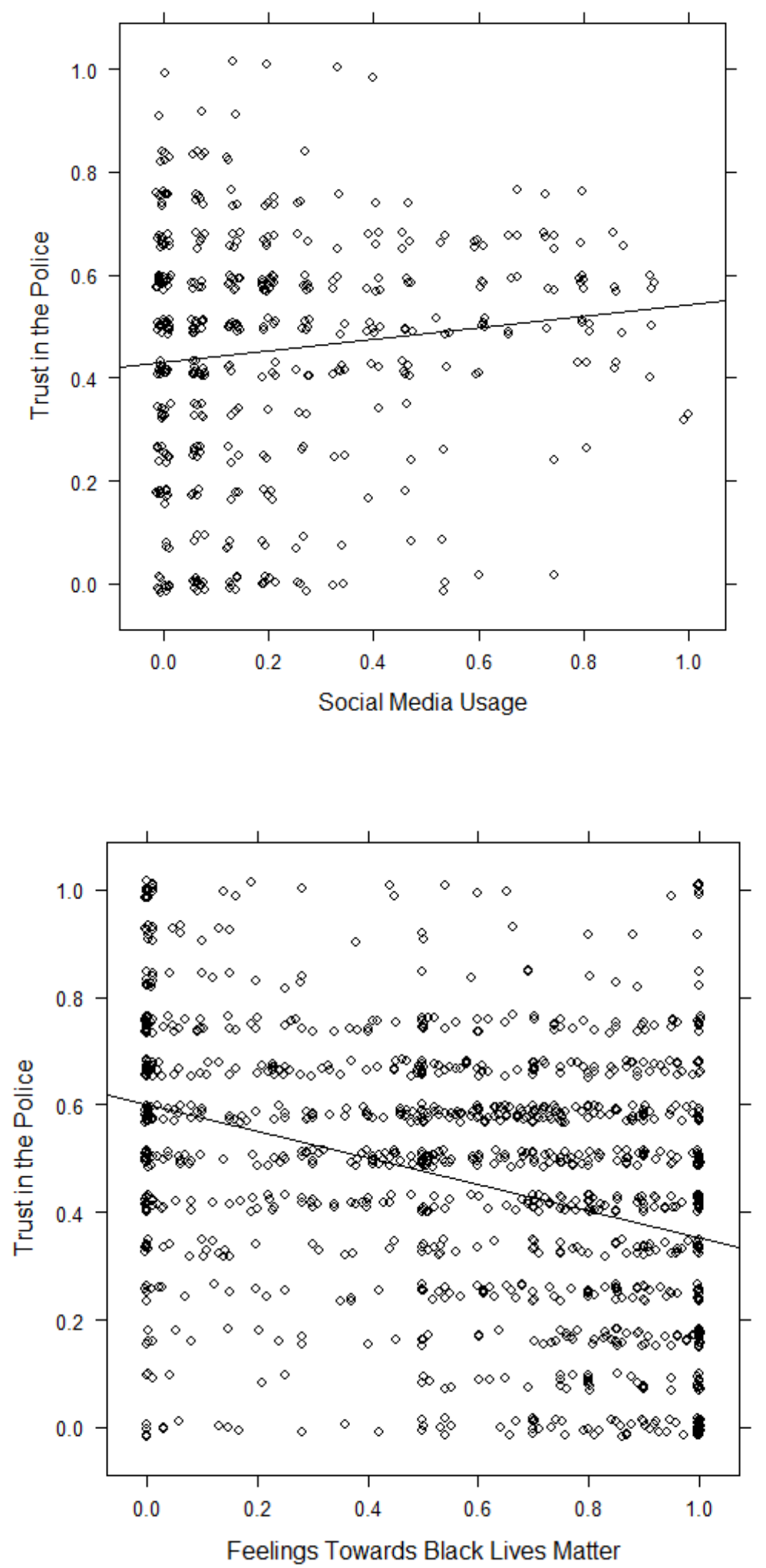


\section{Appendix F}

Scatterplots for relationship between the treatment groups with trust in the government and demographic information (significant ${ }^{3}$ results only)
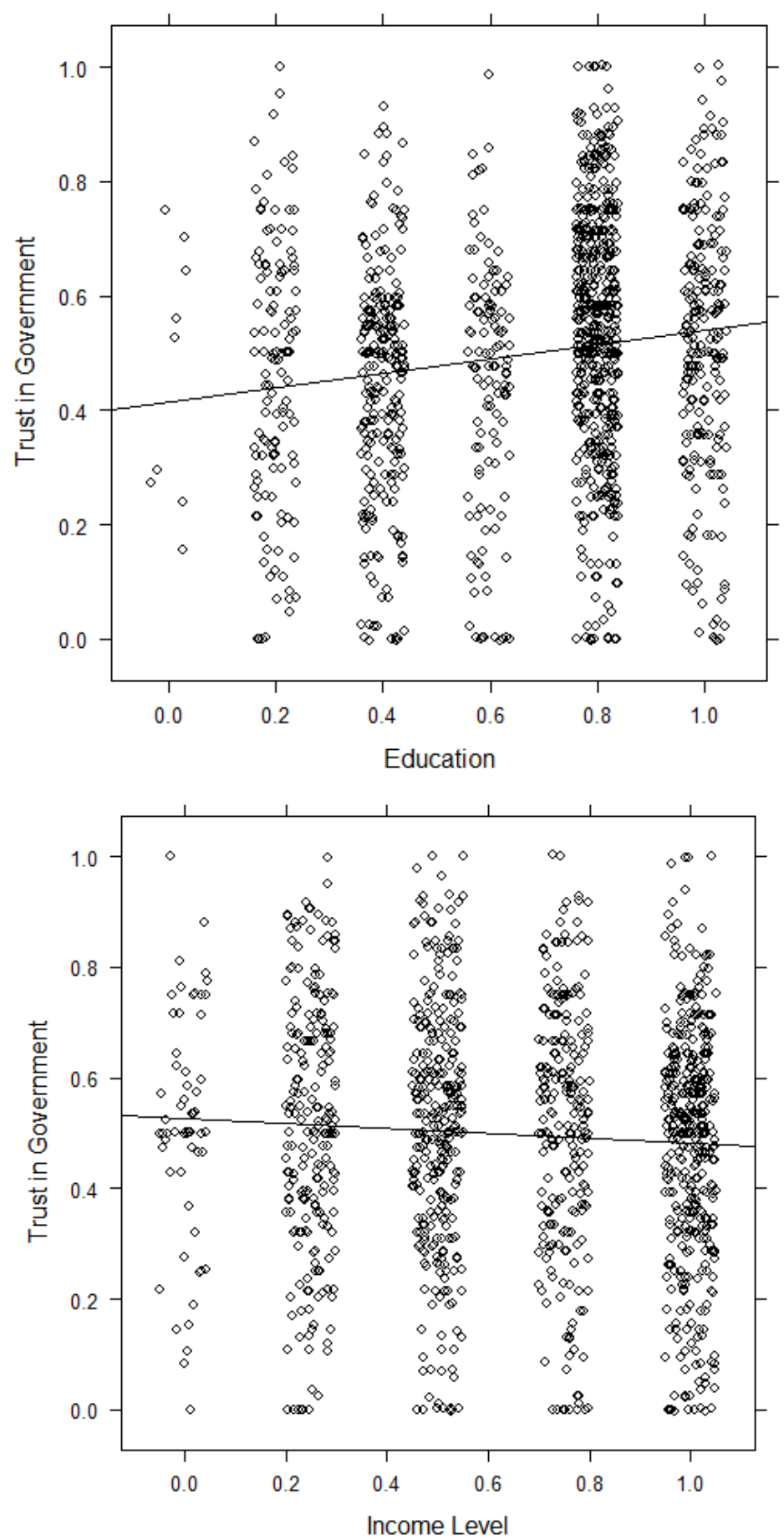

${ }^{3}$ Significant indicates a p-value of $<0.05$ after performing a multivariate regression test 

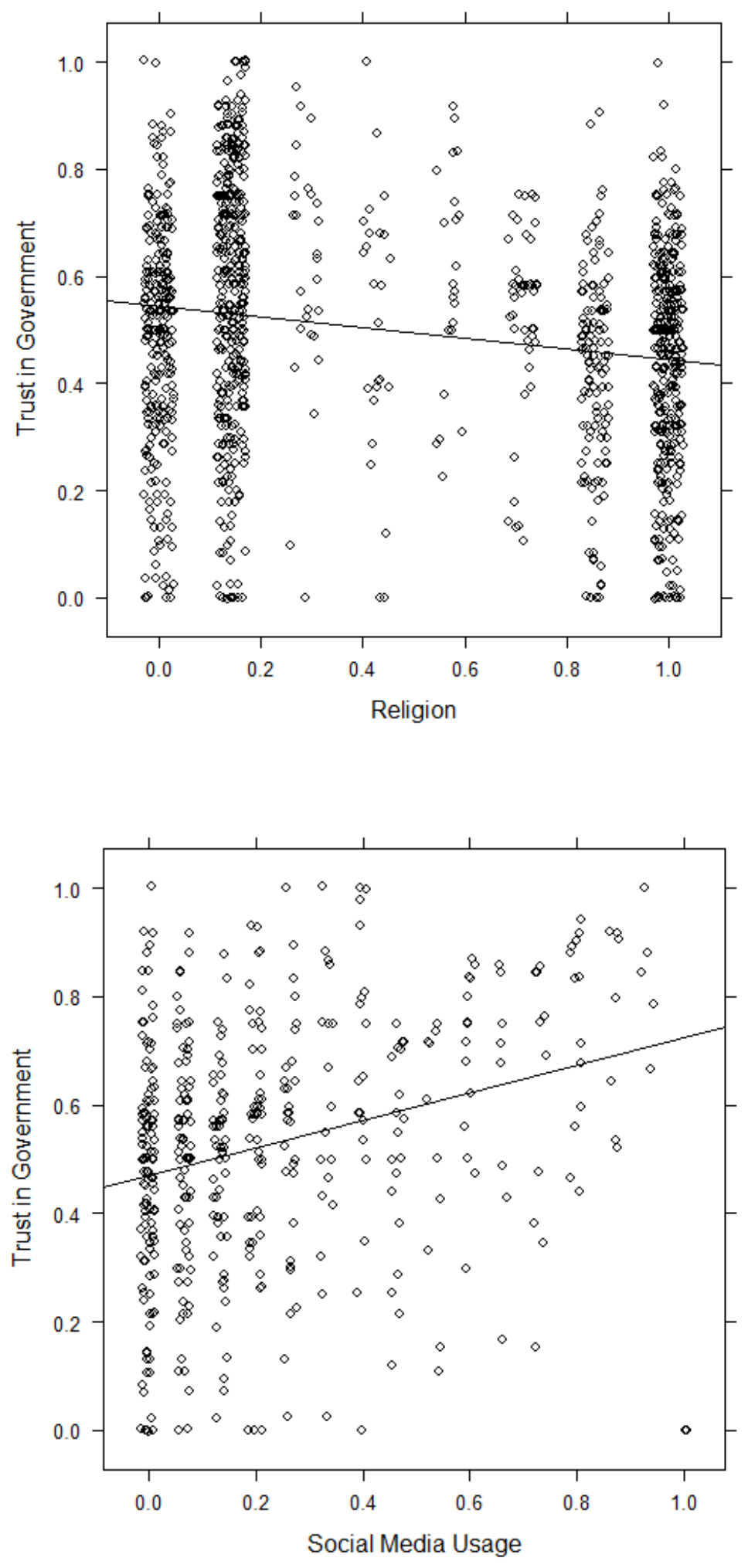


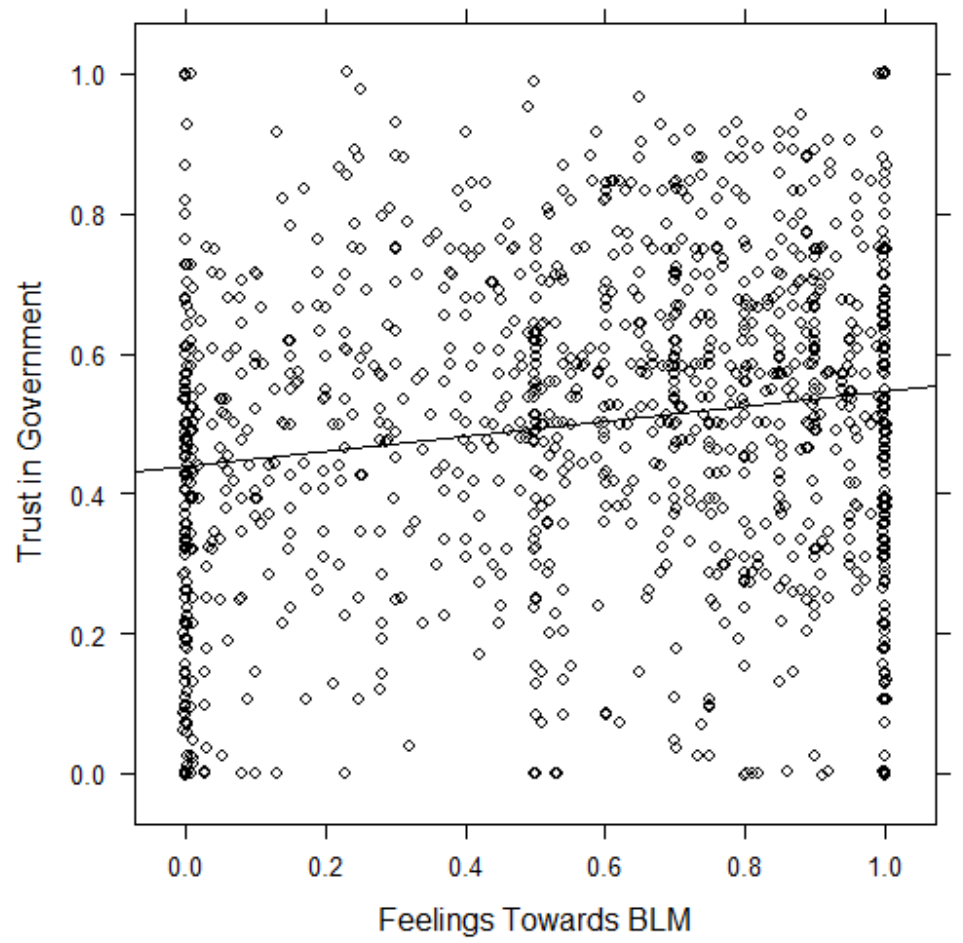




\section{Appendix G}

Interaction plot for relationship between the incidental exposure treatment group and demographic information (significant ${ }^{4}$ results only)

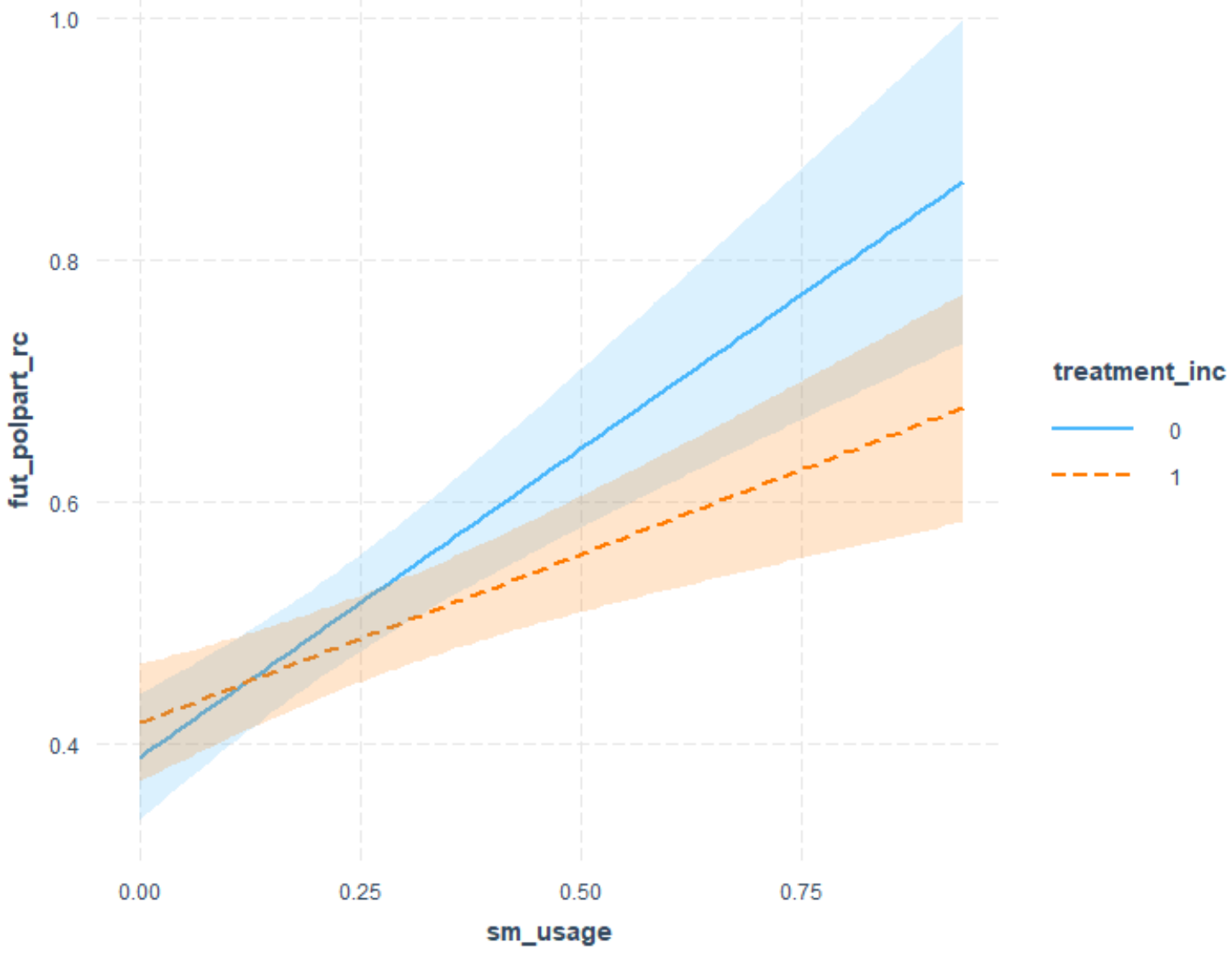

Interaction between social media usage and likeliness to participate in politics within the incidental exposure treatment.

\footnotetext{
${ }^{4}$ Significant indicates a p-value of $<0.05$ after performing a bivariate regression test with interactions
} 


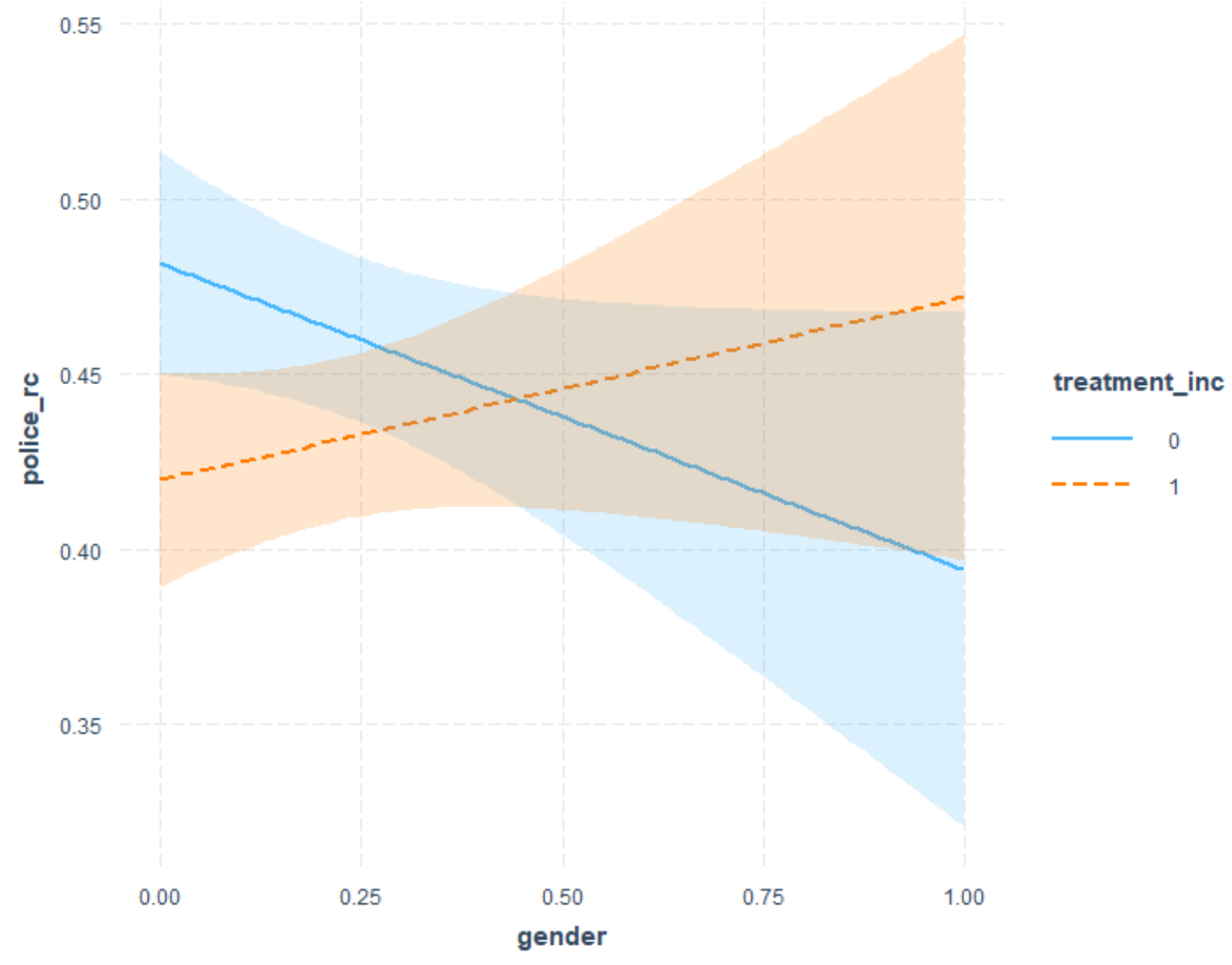

Interaction between gender and trust in the police within the incidental exposure treatment. 


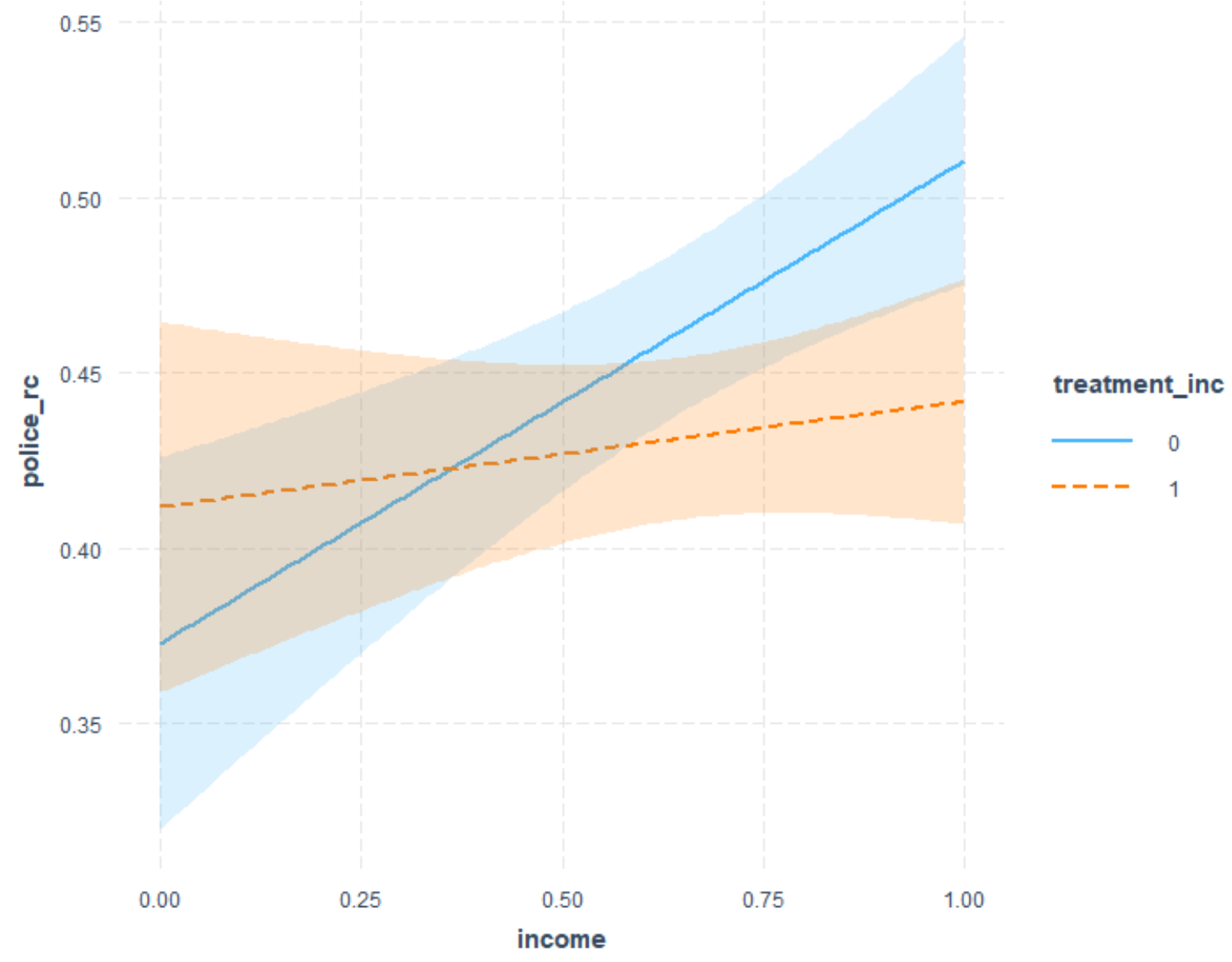

Interaction between level of income and trust in the police within the incidental exposure treatment. 


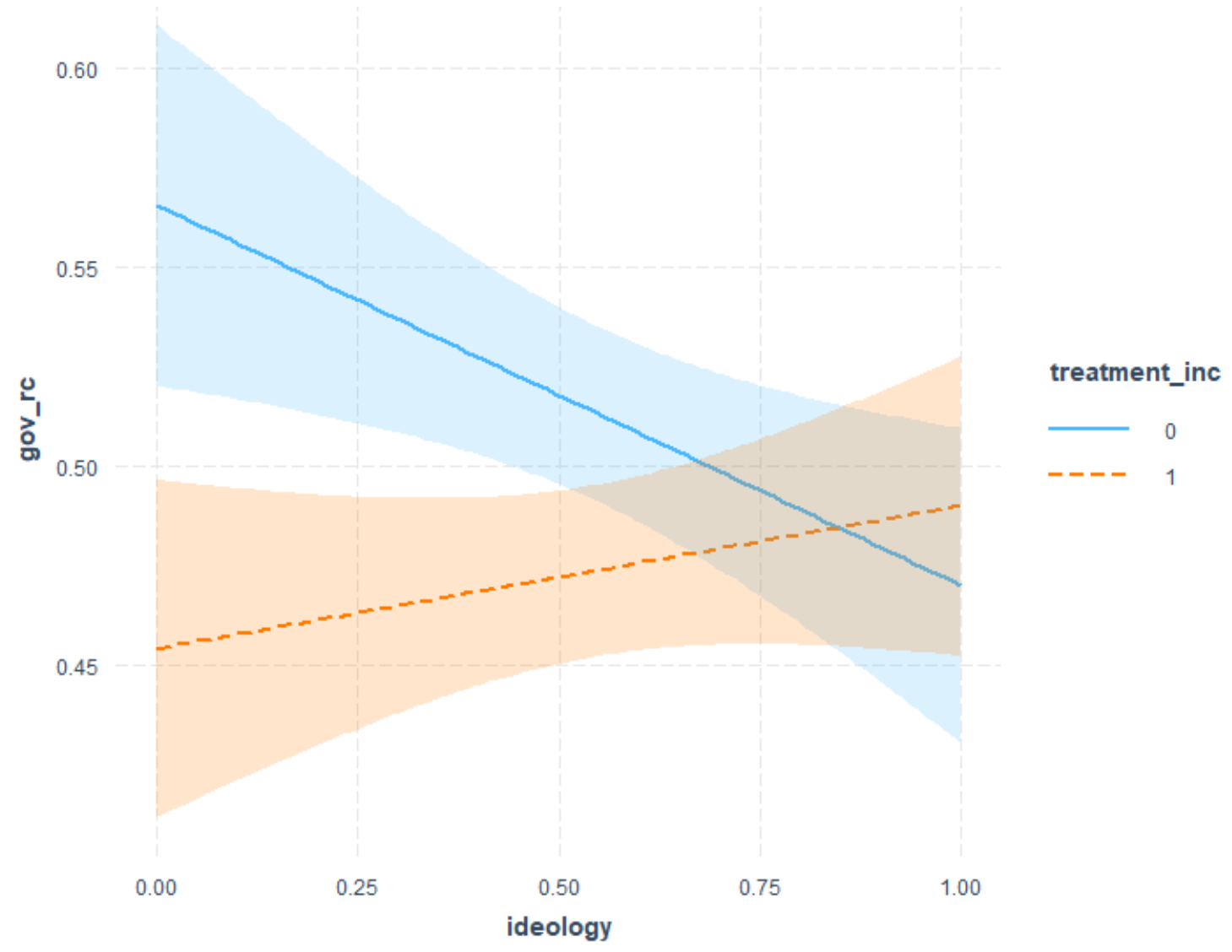

Interaction between race and trust in the government within the incidental exposure treatment. 


\section{CURRICULUM VITA}

NAME: $\quad$ Brianna Berry

ADDRESS: $\quad 709$ S. $3^{\text {rd }}$ Street

Apt. 834

Louisville, KY 40202

DOB: $\quad$ Florence, KY - May 22, 1996

EDUCATION

\& TRAINING: $\quad$ B.A., Music

University of Louisville

2014-2018

B.A., Psychology with a Track in Social Sciences

University of Louisville

2014-2018

Minor, Spanish

University of Louisville

2016-2018

M.A., Political Science

University of Louisville

2019-2021

AWARDS: $\quad$ University of Louisville Dean's List

2015, 20172018

University of Louisville Dean's Scholar

2016

University of Louisville A\&S Outstanding Graduate 2018

RESEARCH: Undergraduate Honors Thesis: The Effects of Musical Training on the Well-Being of Older Adults 